\title{
Novel objects with causal schemas elicit selective responses in tool- and hand-selective lateral occipito-temporal cortex
}

\author{
Anna Leshinskaya ${ }^{1,2 *}$ Mira Bajaj ${ }^{1,3}{ }^{\dagger}$, and Sharon L. Thompson-Schill ${ }^{1}$ \\ ${ }^{1}$ Psychology Department, University of Pennsylvania \\ ${ }^{2}$ Center for Neuroscience, UC Davis \\ ${ }^{3}$ The Johns Hopkins University School of Medicine
}

\begin{abstract}
Tool-selective lateral occipito-temporal cortex (LOTC) responds preferentially to images of tools (hammers, brushes) relative to non-tool objects (clocks, shoes). What drives these responses? Tools have elongated shapes and are more likely to have motor associations, but another essential property is that they exert causal effects on the environment. We tested whether LOTC would respond to novel objects associated with a tool-canonical schema in which their actions cause other events. To do so, we taught male and female human participants about novel objects embedded in animated event sequences, which varied in the temporal order of their events. Causer objects moved prior to the appearance of an environmental event (e.g., stars) while Reactor objects moved after an identical event; objects were matched on shape and motor association. During fMRI, participants viewed still images of these novel objects. We localized tool-selective LOTC and non-tool-selective parahippocampal cortex (PHC) by contrasting neural responses to images of familiar tools and non-tools. We found that LOTC responded more to Causers than Reactors; this effect was absent and weaker in right PHC. We also localized responses to images of hands, which elicit overlapping responses with tools. Across inferior temporal cortex, voxels' tool and hand selectivity positively predicted a preferential response to Causers, and non-tool selectivity negatively so. We conclude that a causal schema typical of tools is sufficient to drive LOTC, and more generally, that preferential responses to domains across the temporal lobe may reflect the relational event structures typical of those domains.
\end{abstract}

\section{INTRODUCTION}

Among the most classic and well-replicated findings in cognitive neuroscience is the observation of an area in lateral occipito-temporal cortex (LOTC) that responds preferentially to images of tools (hammers, rakes, brushes) relative to other object kinds, including artifacts like clocks and shoes (Anzellotti, Mahon, Schwarzbach, \& Caramazza, 2011; Bracci, Cavina-Pratesi, Ietswaart, Caramazza, \& Peelen, 2011; Chao, Haxby, \& Martin, 1999; Garcea \& Mahon, 2014; Martin, Wiggs, Ungerleider, \& Haxby, 1996; Simmons \& Martin, 2011; Valyear, Cavina-Pratesi, Stiglick, \& Culham, 2007; Vingerhoets, Acke, Vandemaele, \& Achten, 2009). Convergently, lesions to LOTC impair the recognition and naming of tools (Brambati et al., 2006; Buxbaum, Shapiro, \& Coslett, 2014; Campanella, D'Agostini, Skrap, \& Shallice, 2010; A. R. Damasio, Tranel, Grabowski, \& Adolphs, 2004; H. Damasio, Grabowski, Tranel, Hichwa, \& Damasio, 1996; Tranel, Damasio, \& Damasio, 1997).

However, the functional role of tool-selective LOTC remains a puzzle. It is not characterized by a profile of

\footnotetext{
*Address correspondence to: Anna Leshinskaya Center for Neuroscience University of California, Davis 1544 Newton Court, Room 209 Davis, CA 95618 anna.leshinskaya@gmail.com

†joint first authorship
}

specific shape selectivity. For example, LOTC is also driven by point-light displays of mechanical (vs biological) motion (Beauchamp, Lee, Haxby, \& Martin, 2002) and animations depicting inanimate (vs animate) interactions among the same set of shapes (Martin \& Weisberg, 2003). Most strikingly, this area responds not only to tools, but also to images of hands, which are highly dissimilar in form (Bracci, Cavina-Pratesi, Connolly, \& Ietswaart, 2016; Bracci et al., 2011; Bracci, Daniels, \& Op de Beeck, 2017). Neither is its role specific to visual recognition. Its preferential response to tools persists with auditorily (Noppeney, Price, Penny, \& Friston, 2006) and visually (Peelen et al., 2013) presented names as well as item-elicited sounds (Doehrmann, Naumer, Volz, Kaiser, \& Altmann, 2008; Lewis, Brefczynski, Phinney, Janik, \& DeYoe, 2005) and is conserved in individuals born blind (Mahon, Anzellotti, Schwartzbach, Zampini, \& Caramazza, 2009; Mahon, Schwarzbach, \& Caramazza, 2010; Mattioni et al., 2020; Peelen et al., 2013).

One hypothesis is that LOTC is driven by motor interaction experience. Action training increases LOTC response to novel shapes (Weisberg, van Turennout, \& Martin, 2007) and its response is larger to objects one tends to interact with relative to less interactive ob- 
jects (Magri, Konkle, \& Caramazza, 2016). However, its role is unlikely in motor execution per se. Damage to areas spanning LOTC affects the recognition of tool-based actions but less so the execution of such actions (Tarhan, Watson, \& Buxbaum, 2016). LOTC responses to observed actions are similar across diverse physical manners of accomplishing a similar goal (Oosterhof, Wiggett, Diedrichsen, Tipper, \& Downing, 2010; Vannuscorps, Wurm, Striem-Amit, \& Caramazza, 2018; Wurm \& Lingnau, 2015). Furthermore, participants born without hands maintain a preferential response to hands and tools in LOTC (Striem-Amit, Vannuscorps, \& Caramazza, 2018), suggesting that the overlap between tool and hand responses is not due to their coordination in motor experience. Overall, LOTC is not simply driven by motor association.

We hypothesize that an important role of LOTC is the retrieval of a causal schema linking objects to their effects. Learning how to interact with objects entails learning such a schema in addition to a motor association. More than their shapes, functional roles are central to the way even young children classify novel artifacts (Futó, Téglás, Csibra, \& Gergely, 2010; Gopnik \& Sobel, 2000; Hernik \& Csibra, 2009; Kemler Nelson, Frankenfield, \& Morris, 2000; Nazzi \& Gopnik, 2003; Oakes \& Madole, 2008; Träuble \& Pauen, 2011; Truxaw, Krasnow, Woods, $\&$ German, 2006). The function of tools like hammers or paintbrushes involves a direct effect on a target, unlike the function of non-tool artifacts like a book or a shoe. In support of a related idea, Bracci and Peelen (2013) find that LOTC responds weakly to objects one acts "on" (like tennis balls or musical instruments) relative to tools, which one acts "with". Here, we test the specific hypothesis that LOTC responds most strongly to objects which participate in a tool-canonical schema in which their actions lead to effects on the environment. We do so by teaching participants about novel objects, whose cause-effect schemas we manipulate, and measuring their effect on the activity in tool-selective LOTC.

\section{METHODS}

\subsection{Overview}

Prior to fMRI scanning, participants were taught about eight novel shapes that each belonged to one of four causal schema conditions (Figure 1). We demonstrated the causal schemas belonging to the objects by systematically embedding each object in a specific animated sequence consisting of an object movement event (e.g., the object rotating) and an ambient event (e.g., stars appearing in the environment). The principal manipulation was whether the object's role in the animated sequence was best described as a Causer or as a Reactor: Causer objects moved prior to the ambient event, whereas Reactors moved afterwards, keeping the component events otherwise identical (Figure 1). We orthogonally manipulated whether the object movement was self-generated (Self-Mover) or elicited by an animated hand (HandMover). Participants memorized the animated sequence that went with each object, then were scanned with fMRI while viewing the objects and recalling their associated animations from memory. We identified tool-selective LOTC using a separate, standard category localizer (Bracci et al., 2011), which allowed us to compare responses to real-world tools vs non-tool artifacts (Figure 2 ). We assessed whether tool-selective LOTC responded to the novel object conditions according to the structure of their associated cause-effect schema, having controlled for factors including object shape, association with an outcome event, association with a hand movement, familiarity, and motor experience.

\subsection{Code Accessibility and Preregistration Materials}

The experimental and analytical methods used in this experiment were preregistered using the Open Science Framework repository and are available at https://osf.io/wzvn2/. Deviations from the preregistered procedures are noted in the manuscript. Custom code for generating and implementing the experimental procedure is also available in the repository. Custom code for neuroimaging analysis is available upon request.

\subsection{Participants}

For the primary experiment, we report the results of 32 participants; to achieve this planned sample size, we scanned 45 participants. Of these, eight were excluded due to excessive head motion and two ended their scan early due to discomfort. Prior to analysis of the primary experimental data, localizer data were individually inspected for quality. In three participants, localizer data were exceptionally noisy with no clear activation for the main contrast of interest (tools vs non-tools) and were thus excluded on that basis. This resulted in the exclusion of 13 participants, who were replaced to fulfill the counterbalancing criteria. This resulted in the final sample of 32 participants (19 female), with a mean age of 22.66 ( $\mathrm{SD}=3.02$, range $18-29)$.

We recruited participants from the University of Pennsylvania community using the Experiments@Penn website. Procedures were approved by the Institutional Review Board at the University of Pennsylvania and all participants provided written informed consent prior to participation.

Participants were required to be between 18-35 years of age, right-handed, and eligible to be scanned with MRI. Compensation for participating was $\$ 60$.

We also report the results of a follow-up experiment $(\mathrm{n}=10)$ which used the same recruitment, compensa- 
A

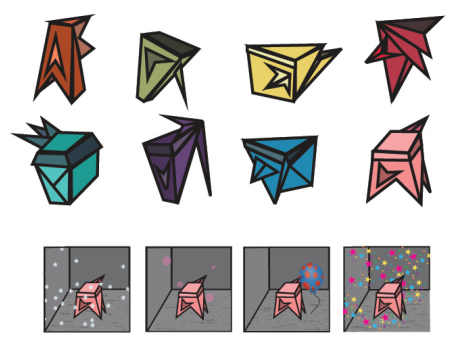

B

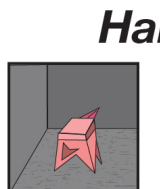

Hand-Causer

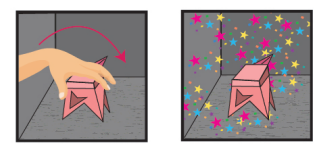

Hand-Reactor
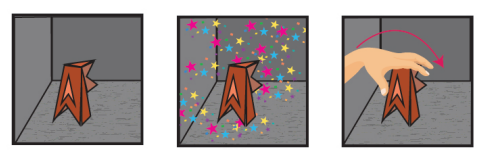

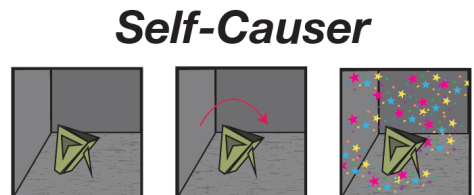

Self-Reactor
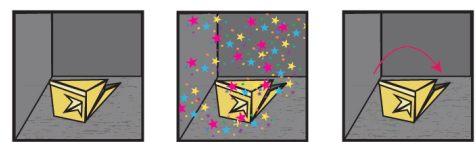

C

Pre-Scan Test

Which objects were moved by a hand before the stars?

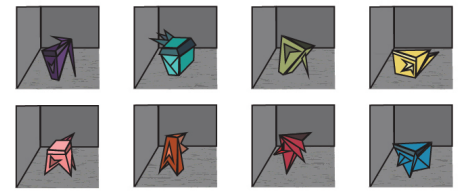

D

\section{In-Scan Retrieval Task}
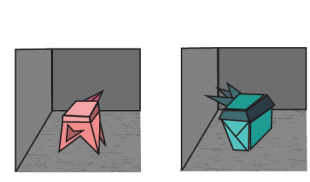

$18 \%$ of trials

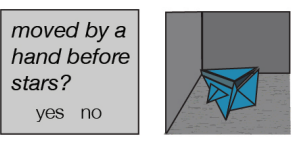

$3.4-3.6 s \quad 4 s$

Figure 1. Figure 1. A. The eight novel object shapes (top) and still frames from the four kinds of ambient events (bottom): snow, bubbles, balloon, and stars. B. Example of the four animation conditions in the experiment. A unique object shape appeared in each distinct event sequence. The Hand Causer object was moved by a hand prior to an ambient event; the Hand Reactor object was moved after an ambient event; the Self Causer object moved on its own prior to an ambient event, and the Self Reactor moved after an ambient event. Shape assignments were counterbalanced across participants and each participant saw two instances of each condition, each with one of two ambient events selected from the set of four shown in A. C. Prior to scanning, participants watched the animated event sequences featuring each object, followed by test questions probing their knowledge, an example of which is shown here. D. During fMRI scanning, still images of each object were shown in randomized order (3.4-3.6 s ISI); $18 \%$ of trials were followed by a question probing participants' knowledge of the event sequence that went with the object they had just seen.

A

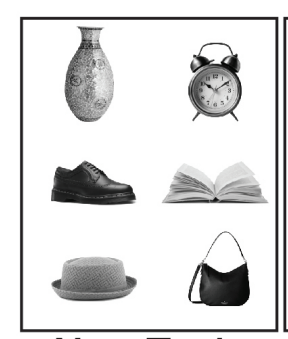

Non-Tools

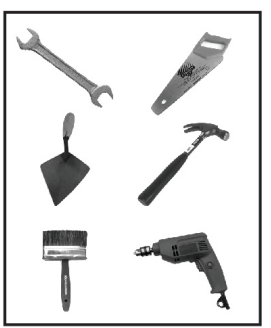

Tools

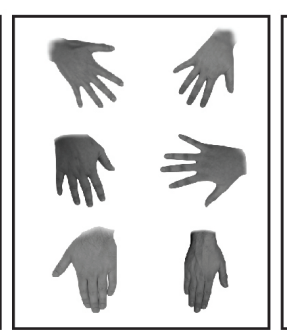

Hands

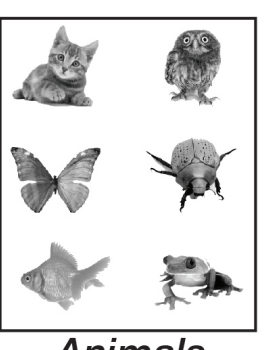

Animals
B

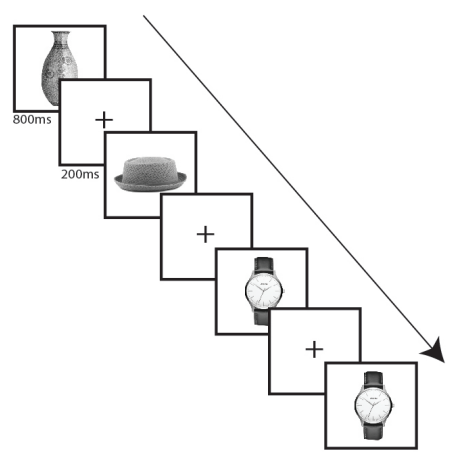

Figure 2. Figure 2. A. Example images belonging to each of the four conditions in the localizer task: Non-Tools, Tools, Hands and Animals. B. Localizer task procedure, in which images were shown blocked by condition and in randomized order, with a 1s ISI. Participants hit a button when an identical image repeated twice in a row, as in the last trial pictured here. 
tion and exclusion methods. Of the 12 participants we scanned, one was excluded for excessive motion and one ended the scan early due to discomfort. The final sample had a mean age of 22.40 (range $19-27$ ) and 8 were female.

\subsection{Stimuli \& Materials}

\subsubsection{Training Task}

Prior to fMRI scanning, participants learned about the eight different animated event sequences, each involving a specific, novel, distinctly shaped and colored geometrical object (Figure 1). All animated sequences involved a movement of the object and an ambient event (something appearing and disappearing in the background, such as stars or bubbles; Figure 1). They belonged to one of four conditions created by crossing two factors: Movement Type and Causality. Movement Type was either Self, in which the object moved on its own (it rotated back and forth) or Hand, in which an animated hand reached in, grabbed the object, and rotated it back and forth. Causality affected the order of events: in the Causer condition, the object moved prior to the ambient event, whereas in the Reactor condition, the object moved afterwards. This was manipulated by re-ordering the same frames. Crossing these two factors created 4 conditions: Self Causer, Self Reactor, Hand Causer, and Hand Reactor. These four conditions had two sets of specific animations, which varied in the nature of the ambient event involved (e.g., in set 1, the ambient event was bubbles, in set 2, stars). Each of the eight animations involved a uniquely shaped object that was systematically mapped to its condition for each participant, but counterbalanced across participants (see below).

Animations were created by hand-drawing static frames using Adobe Illustrator and concatenating them into GIFs for each separable component event (i.e., each movement type and each ambient event for each object shape). These were then recombined to make the full event sequences for each condition, ensuring that the components were identical. GIFs were created from individual frame files using Matlab (Mathworks).

All animations took place against a gray background resembling an empty room. Each sequence began with the object smoothly entering the room (13 100-ms frames, total length $1300 \mathrm{~ms}$ ). In Causal sequences, the movement event was shown first, followed by the ambient event; in Reactor sequences, this order was reversed. In all cases, each movement and ambient event segment comprised $29100 \mathrm{~ms}$ frames (2900 ms). The Selfmovement event involved the object rotating 10 degrees forward and back; the Hand-movement events involved an animated hand reaching in, grasping the object and tilting it forward and back, then leaving; both movement events were of equal total duration. Following the movement and ambient events, the object then stayed still for $800 \mathrm{~ms}$. It then repeated the movement and ambient pair and the $800 \mathrm{~ms}$ pause two more times, for a total of three, and then smoothly exited the room (2900 ms). This full set of events, including the repetition, composed the "animated event sequence" for each object shown in the training task.

To control condition comparisons for shape, the eight geometric objects were assigned to the four conditions in counterbalanced fashion with the following procedure: The eight objects were split into two sets of four, A-D and E-H. Within each set, we ensured that each object appeared in each condition equally often, creating 16 assignment options. We additionally ensured that for each planned comparison (e.g., Causers > Reactor within Movement Type), pairs were perfectly counterbalanced for shape (i.e., equal numbers of comparisons in which $\mathrm{A}$ is the Causer and $\mathrm{C}$ is the Reactor as vice-versa). The two sets were themselves paired such that all pair combinations appear equally often in each condition (e.g., $A \& E, A \& F, A \& G$, and $A \& H$ are members of each condition equally often, and so on for the pairings of $\mathrm{B}$, $\mathrm{C}$, and $\mathrm{D}$ in place of $\mathrm{A}$ ).

There were four kinds of ambient events: pink bubbles floating across the scene ('bubbles'), snowflakes sweeping from left to right ('snowflakes'), a balloon floating across the screen ('balloon'), and multi-colored stars sweeping from left to right ('stars'). Each type of event was created in identical fashion in the context of each object shape. The selection of these events was randomized across participants, but each event appeared equally often in each condition. For each participant, two ambient event types were selected (out of the set of four) and assigned to each shape set. That is, one ambient event was shown with shape set A-D, and the other with E-H. The combination of event and shape selections was randomized. There were 12 ways to select two ambient events from the set of four and assign them to the two object sets; one of these options was selected randomly for each participant, independently of the object-condition assignments. Overall, these counterbalancing and randomization efforts ensured that the experimental conditions did not systematically differ in terms of the object shapes or ambient events shown in their animated sequences.

\subsubsection{Category Localizer}

Participants performed a category localizer task during fMRI in which they saw grayscale images of objects from 4 categories: Tools (hammers, drills, wrenches, spades, paintbrushes, saws), Hands, Animals (e.g., birds, reptiles, kittens), and Non-Tools (hats, bags, clocks/watches, books, vases, shoes). Non-Tools were all small, inanimate artifacts which do not typically have a direct effect on the environment when used in typical fashion. Stimuli were provided by authors of previously published research on category-selective responses in the visual system (Bracci 
et al., 2011; Konkle \& Caramazza, 2013). Examples of stimuli are shown in Figure 2.

\subsection{Procedure}

\subsubsection{Overview}

Participants first performed the training task, in which they saw all of the eight animated sequences and learned to associate each sequence with their participating object shape. They then entered the fMRI scanner, where they reviewed the sequences, performed a retrieval task with the novel objects, and saw the category localizer.

\subsubsection{Training task}

Participants began the training task 1.5 hours prior to scanning. They were instructed to memorize the animated event sequence belonging to each object. The task was implemented using JavaScript and presented in a web-browser. They saw each of the eight animated sequences (featuring each of the eight objects) one at a time, fifteen times over five blocks or until criterion (see below). The order of presentation was randomized across blocks but constrained such that each sequence appeared at least twice but not more than seven times in each block. Each block thus contained 20-28 animated sequences.

After each block, participants were asked 12 questions to assess their learning (Figure $1 \mathrm{C}$ ). Each question posed a query regarding the animations they had seen and asked participants to select the objects of which it was true. For example, "which object(s) were moved by a hand before the stars?". Images of all eight objects were shown in randomized positions and participants responded by selecting any number of the objects. Eight of these questions were specific to both condition and the specific ambient event, such that there was only one correct answer (e.g. "which object(s) tilted on their own before the bubbles?"). The other four questions asked more generally about the movement or ambient event types involved, such that there were four correct answers ("which object(s) tilted on their own?", "which object(s) were moved by a hand?", "which object(s) involved the bubbles in their videos?", "which object(s) involved the stars in their videos?"). Questions were presented in a randomized order.

At the end of the question set, participants were given an overall score (e.g., "You answered 8/12 questions correctly"). Each block took approximately 5-7 minutes to complete. If participants achieved a score below perfect on the final block, they were encouraged to complete another block of training.

In a separate group of participants $(n=32)$ who only completed the training task, we saw higher accuracy for the Self-Causer objects compared to the Self-Reactor objects on the questions following the first block of training (but no other differences). We saw a similar trend in the first several fMRI participants. We thus adjusted the training task to show more of the SelfReactor objects earlier in the training sequence (and fewer later). Thus, the Self-Reactor objects were shown four times in the first block, whereas the Self-Causer objects were shown two times; this was balanced out in the fourth block, where the Self-Reactor objects were shown twice and the Self-Causer four times.

After they completed the training task, participants were given a sheet of printed object images and asked to write above each image a description of its corresponding events (e.g., 'moved by a hand before stars appeared'). If they were unsure about any object, they were asked to complete additional training blocks until they felt comfortable. Overall, eight participants completed additional training blocks (4 participants completed 1 extra block, 1 participant completed 2 extra blocks, and 3 participants completed 3 extra blocks).

\subsection{3 fMRI acquisition parameters}

MRI data were collected on Siemens Tim-Trio 3T scanner at the University of Pennsylvania Center for Neuroimaging. A 64-channel coil was used. Structural scans were acquired with an MPRAGE sequence with $0.8 \mathrm{~mm}$ isotropic voxels, a field of view of $256 \mathrm{~mm}$, and matrix size of $320 \mathrm{~mm} \times 320 \mathrm{~mm} \times 320 \mathrm{~mm}$. Functional scans were acquired with an interleaved multi-band EPI sequence (173 volumes/346 seconds, 72 slices of $2 \mathrm{~mm}$ isotropic voxels; no gap; $\mathrm{TR}=2000 \mathrm{~ms}$; $\mathrm{TE}=30.0 \mathrm{~ms}$; Multi-band acceleration factor $=3$; Flip angle $=75^{\circ}$; FoV $=220 \mathrm{~mm} ;$ matrix size $=110 \times 110 \mathrm{~mm}$ ).

\subsubsection{Anatomical scan and training task review}

The scan session began with a structural scan. During this time, participants saw a review of the animations they had seen in the training. Each of the eight animated sequences was shown three times in randomized order, in similar manners except that the object paused for additional time before its animation occurred; participants were instructed to visualize the animations of each object once it appeared. This review was repeated twice during the $\sim 6$ minutes of anatomical scanning.

\subsubsection{Retrieval task}

In the retrieval task, participants saw still images of each novel object, i.e., with no animations, one at a time (Figure $1 \mathrm{D}$ ). This was designed to emulate the circumstance in which images of tools are shown and their action properties are associatively retrieved. Each image appeared on screen for a jittered duration of 3.4, 3.5 , or 3.6 seconds (three of each duration per run). Here, participants were also instructed to try to explicitly recall each object's corresponding event sequence while viewing the image, in preparation to answer questions which appeared following image presentation on $18 \%$ of trials ('catch' trials). Questions were shown for four 
seconds, fast enough to encourage participants to be prepared for them by retrieving their knowledge ahead of time. Each object image was shown 72 times in total, nine times per run over eight runs.

There were eight types of catch trial questions. Four types were specific to one object (e.g. "Moved by a hand before the stars?"), and four applied to four objects (e.g "Moved by a hand?"). Each question type was shown twice for each object (for a total of 16 per object). Each of these 16 questions were assigned randomly among that object's 72 presentation trials across the experiment (the number of questions per run could vary). No feedback was given. Null trials (a fixation cross shown for four seconds) were also distributed through the scan and shown subsequently to two of the object image trials, chosen at random. Runs concluded with the presentation of a fixation screen of variable duration to reach a total exact length of $346 \mathrm{~s}$, to accommodate any variance in exact duration due to varying numbers of questions.

\subsubsection{Category localizer}

Each trial showed one object image on a white background for $800 \mathrm{~ms}$ followed by $200 \mathrm{~ms}$ of fixation (Figure $2 \mathrm{~B})$. There were 36 images per condition, each shown twice. Trials were blocked by condition, with six trials per block and twelve blocks per condition per run. During image presentation, participants performed a one-back exact image repetition detection task. Repetitions were added randomly ( 1 or 2 per block, or $12.5 \%$ of trials) but their total was equated across conditions. There were two runs of $426 \mathrm{~s}$ duration each.

\subsubsection{Post-scan ratings}

. After the scan, participants rated each animated sequence on its level of perceived causality and tool-like quality ('tool-like-ness'). Participants saw each animation in a randomized order with both questions below. Causality questions asked to what extent the first event seemed to cause the second event (e.g., "To what extent did the hand tilting the object seem to cause the snow?"); Tool-likeness questions asked, "To what extent did the object seem tool-like?" Responses were on a scale of 1-5, with the answer choices being: " $1=$ Not at all", " 2 = Very little", " $3=$ Somewhat", " $4=$ Quite a bit", and " $5=$ Very much so".

\subsection{Experimental Design and Statistical Analysis}

\subsubsection{Preprocessing}

Preprocessing was performed using AFNI software (Cox, 1996). The data were slice-time corrected using the function 3dTshift and then high-pass filtered (using $3 \mathrm{dFourier)}$ with a cutoff of $0.008 \mathrm{~Hz}$. The data were motion-corrected to the 10th volume of the first functional run with $3 \mathrm{~d}$ Volreg. Linear and polynomial trends up to the 3 rd level were removed with $3 \mathrm{dDetrend}$. The localizer runs were smoothed with a $6.0 \mathrm{~mm}$ Gaussian filter and the retrieval runs were smoothed with a 3.0 $\mathrm{mm}$ Gaussian filter for multivariate analyses and $6.0 \mathrm{~mm}$ for univariate analyses. Participants with an overall head displacement of $>3.5 \mathrm{~mm}$ were excluded and replaced. Linear modeling was done using $3 \mathrm{dDeconvolve;} \mathrm{details}$ of each model are described below.

\subsubsection{Linear Modeling: Retrieval Task}

A linear model was fit to the data with a regressor for each of the eight objects, one for all of the question periods, and derivatives of the six motion realignment parameters. For whole-brain univariate analyses, t-tests were used to analyze the main effect of Causality (Causer vs. Reactor) and Movement Type (Hand vs. Self) as well as planned comparisons between Self-Causer vs. Self-Reactor, and Hand-Causer vs. Hand-Reactor. Whole-brain statistical maps were corrected for multiple comparisons using a cluster-size permutation. Null distributions of maximal cluster sizes were generated by shuffling the labels in the linear model within each subject (generating 10 noise maps each) and performing 1000 iterations of the group analyses. At each iteration, one noise map was chosen from the set generated for each subject and entered into group analyses performed exactly as in the non-shuffled data.

For ROI analyses (see ROI definition, below), linear model fits (t-values) for each participant in all voxels in the ROI were extracted, and averaged across voxels. These were entered into an ANOVA using the $\mathrm{R}$ function 'aov' with block 1 training accuracy as a regressor of non-interest (see Behavioral Results) and Movement and Causality as regressors of interest (all within-subject). Pairwise t-tests were used for planned comparisons between Self-Causer vs Self-Reactor and Hand-Causer vs Hand-Reactor.

\subsubsection{Linear Modeling: Category Localizer}

Each of the four image conditions (Tools, Non-Tools, Animals, Hands) and Fixation were included as regressors in a general linear model along with derivatives of the six motion realignment parameters. Planned contrasts for Tools $>$ Non-Tools, and exploratory contrasts between other categories (see below), were performed using t-tests.

\subsubsection{ROI Definition}

Category localizer data were used to define functional ROIs according to the following general procedure. For a given contrast, a group statistical map (t-test) was used to define group-level contiguous clusters above a specific voxel-level threshold. Cluster significance was established with permutation analysis over cluster sizes (as described above). Clusters were selected to serve as ROI boundaries if they passed a corrected significance value of $\mathrm{p}<.05$ 
and were localized consistently with prior reports for a similar contrast and/or specified in the preregistration. We then defined subject-specific ROIs within these group clusters using individual functional data, by finding the $n$ contiguous voxels that showed the strongest effect for that individual, where $n$ is either pre-specified or a free parameter (see below). If no voxels above 0 were found in this area for that individual, no data for that ROI for that participant was included. This approach was preregistered; however, two parameters were set on the basis of the observed localizer data (not the test data from the novel objects): the initial pre-cluster grouplevel voxel-wise threshold and the value of $n$. These are described more in the specific ROI definitions described below.

Tools vs Non-Tools Our major planned contrast was between Tools and Non-Tools. T-tests across the group were used to compare responses to Tools and Non-tools and thresholded voxel-wise at $p<.0001$. Permutation analysis indicated that group clusters over 24 voxels in size were significant at $p<.05$ given a pre-cluster threshold at this threshold. For Tools $>$ Non-Tools, this revealed two areas, left LOTC (535 voxels) and left IPS (286 voxels), highly consistent with prior findings (Bracci et al., 2016; Garcea \& Mahon, 2014; Striem-Amit et al., 2018). For Non-Tools $>$ Tools, we identified left and right parahippocampal cortex (left PHC: 60 voxels; right PHC: 363 voxels) and bilateral occipital lobe (right OC: 905 voxels; left OC: 408 voxels), consistent with prior findings on large and non-manipulable inanimate objects (Konkle \& Caramazza, 2013; Magri et al., 2016). One participant showed no positive effects within the IPHC ROI and was thus excluded from analyses involving $\mathrm{IPHC}$. We selected the more anterior PHC ROIs for analysis as we expected that these were more likely to show high-level effects and sensitivity to learning. We report data from the occipital ROIs in the supplement.

For the value of $n$ (individual ROI size in terms of the number of most selective voxels), our preregistration had initially specified 200. To determine the spatial specificity of the results, we additionally we performed a sweep of this parameter value, including 25, 50, 100 and 200. In Non-Tool selective left PHC, the group cluster only had 60 voxels, and thus used $n=25$ and 50 only. For follow-up/exploratory analyses, we used the most specific (smallest) ROIs to support stronger arguments regarding specificity.

Tool $\&$ Hand Conjunction To define Tool \& Hand selective LOTC, we created conjunction maps by intersecting four contrasts: Tools $>$ Non-Tools, Tools $>$ Animals, Hands $>$ Non-Tools and Hands $>$ Animals. Each of the four maps was first thresholded voxel-wise at $p<.01$. For voxels passing this threshold for all maps, the minimum of the four p-values was taken to reflect combined significance. This combined p-value map was in turn thresholded at $p<.0001$ to identify regions of interest. This identified three areas: left LOTC (297 voxels), left IPS (1183 voxels), and right IPS (375 voxels). To define individual ROIs within each area, we selected the $\mathrm{n}$ most selective voxels for each individual as follows: We subtracted a participant's $t$-values for each contrast (Tools - Non-tools, Tools - Animals, Hands - Non-tools, Hands - Animals) and selected voxels in which each value was greater than 0 , then summed their values. The individual ROI was selected as the $\mathrm{n}$ contiguous voxels with the maximal summed value.

\subsubsection{Whole-brain Contrast for Causers vs Reactors}

T-tests across the group were used to compare responses to Causers and Reactors and thresholded voxel-wise at $p<.001$. Permutation analysis indicated that group clusters over 127 voxels in size were significant at $p<$ .05 given a pre-cluster threshold at this threshold.

\subsubsection{Ventral Stream Preference Modeling}

To query the relationship between category-selectivity and novel-object preferences in a more bottom-up fashion, we identified all inferior temporal (IT) ventralstream voxels and entered their responses to the four localizer categories and the four novel object conditions into a general linear model for each participant. To define voxels belonging to the ventral stream, we used the overall magnitude of any category preference from the category localizer GLM (see Linear Modeling: Category Localizer). We took the cross-participant mean response to each of the four localizer categories and identified the maximum of these values. We then thresholded this group-average, category selectivity magnitude at $t>$ 1.75, which revealed a swath across bilateral inferior temporal cortex spanning category-selective areas as commonly reported in studies of the large-scale organization of the visual ventral stream (Konkle \& Caramazza, 2013, 2016; Long, Yu, \& Konkle, 2018). We separately defined the left and right IT (right: 6058 voxels; left: 5500 voxels). Our objective was to predict the magnitude of the Causer vs Reactor difference for novel objects on the basis of 4-way category preference among the realworld, localizer objects. We thus defined a linear model for each participant which predicted the Causer-Reactor difference from the response ( $t$-value) to each of the four categories in the localizer data.

\subsection{Follow-Up Experiment}

We performed a follow-up experiment with 10 new participants to evaluate neural responses to perceiving the animated event sequences, as opposed to recalling information about them from still images. To this end, this group of participants performed the training task rather than a retrieval task during scanning. They viewed the same 8 animations as before, and intermittently an- 
swered questions about the animation they just saw using the same questions as in the retrieval task in the main experiment. They were instructed to try to learn which object went with which animation, and were probed on their knowledge between runs using the same tests as the training task in the main experiment. fMRI trials had a jittered ITI of between $2.9-3.3 \mathrm{~s}$, and each condition was shown 45 times over the course of 5 runs in the scan. Each animation type was followed by each of 8 question types once, their order randomized. Runs contained 72 trials each and lasted 5.83 minutes. Participants viewed two training blocks prior to scanning as a practice. They also performed a category localizer task just as above, in order to identify functional ROIs.

Data from the novel objects training task were analyzed with a GLM modeling whether participants were viewing an ambient or an object-based (self-movement or hand-movement) event; question periods were modeled as a single separate regressor. Another GLM modeled each of the 8 conditions during viewing, and a regressor for question periods. To define Tool-selective LOTC and Hand and Tool Selective LOTC ROIs, we used the group clusters from the main experiment and defined individual ROIs within those areas using the fMRI data collected here, in the same manner as above. We report the results of this follow-up experiment at the end of the Results section, which otherwise concerns the primary, memory retrieval experiment.

\section{RESULTS}

\subsection{Training Task Performance}

Participants responded to questions following each of five (or more) blocks of training. Following their final block of training, participants reached ceiling accuracy in all conditions (Self-Causer: $M=99.61 \%$, $S D=1.63$; Hand-Causer: $M=99.61 \%, S D=1.63$; SelfReactor: $M=100 \%, S D=0.00$; Hand-Reactor: $M=$ $99.87 \%, S D=0.74)$. There was no main effect of movement-type $(F(1,31)=1.00, M S E=0.00, p=.325)$ or causality $(F(1,31)=1.98, M S E=0.05, p=.169)$ on participants' accuracy, and no interaction $(F(1,31)=$ $1.00, M S E=0.00, p=.325$ ). Pairwise tests between conditions showed no significant effects $(p>.161)$. Pre-final blocks of training likewise did not show accuracy differences, except for the first block (Self-Causer: $M=$ $81.25 \%, S D=15.23$; Hand-Causer: $M=77.60 \%, S D=$ 14.23; Self-Reactor: $M=80.60 \%, S D=13.86$; HandReactor: $M=76.30 \%, S D=15.57)$, in which we saw a significant main effect of Movement Type $(F(1,31)=$ $6.00, M S E=7.27, p=.020$, partial $\left.\eta^{2}=0.162\right)$ such that the Self moving objects had higher accuracy than the Hand moved objects. Given this significant behavioral difference, which could reflect differences in the nature of the learning process or memory, we included first-block training accuracy as a within-subject regressor in ROI analyses. There were no other effects, including no main effect of Causality $(F(1,31)=0.30, M S E=0.44, p=.588)$ and no interaction $(F(1,31)=0.02, M S E=0.05, p=.881)$. Pairwise tests between individual conditions showed no significant effects $(p>.11)$.

\subsection{In-Scan Task Performance}

During the in-scan retrieval task, participants were highly accurate in each condition (Self-Causer: $M=$ 85.01\%, $S D=18.38$; Hand-Causer: $M=85.13 \%, S D=$ 16.84; Self-Reactor: $M=85.24 \%, S D=15.28$; HandReactor: $M=85.25 \%, S D=15.82)$. There was no main effect of condition, either for Movement Type $(F(1,31)=$ $0.00, M S E=0.00, p=.965) \quad$ or Causality $(F(1,31)=$ $0.02, M S E=0.00, p=.901)$ and no interaction $(F(1,31)=$ $0.00, M S E=0.00, p=.957)$. No pairwise tests between conditions showed a significant effect (all $p>.895$ ).

\subsection{Causality and Tool-Likeness Ratings}

After completing the scan, participants rated each of the objects on two 1-5 scales, Causality and Tool-likeness. The Causality scale probed to what extent participants perceived the first event in the sequence to have caused the second event in the sequence. We note that all animations were expected to be rated as somewhat causal, as even in the Reactor sequences, the ambient event could be seen as influencing subsequent the object movement. Accordingly, causality ratings revealed that participants rated most of the sequences as 'somewhat' causal (Self-Causer $M=3.17, S D=1.12$; Hand-Causer $M=3.00, S D=1.11 ;$ Self - Reactor $M=2.89, S D=1.27$; Hand-Reactor $M=2.70, S D=1.13)$.

There was, however, a main effect of Causality $\left(F(1,31)=6.31, M S E=2.67, p=.017\right.$, partial $\left.\eta^{2}=0.169\right)$, demonstrating that participants' ratings were higher for the Causer objects than for the Reactor objects. There was no main effect of Movement Type $(F(1,31)=$ $1.45, M S E=1.03, p=.237)$ and no interaction $(F(1,31)=$ $0.00, M S E=0.00, p=.952)$. Pairwise tests showed that the Self-Causer animations were seen as more causal than the Hand-Reactor animations $(t(31)=2.65, p=.012)$. No other effects were significant (all $p>.065$ ).

The Tool-likeness scale rated how 'tool-like' participants perceived each object to be. Across conditions, objects were seen as 'very little' or 'somewhat' tool-like (Self-Causer: $M=2.41, S D=1.04$; Hand-Causer: $M=2.72, S D=1.23$; Self-Reactor: $M=2.69, S D=1.22$; Hand-Reactor: $M=2.69, S D=1.06$ ).

There was no main effect of Movement Type $(F(1,31)=2.49, M S E=0.78, p=.125) \quad$ or $\quad$ Causality $(F(1,31)=1.15, M S E=0.50, p=.292)$ and no interaction $(F(1,31)=1.54, M S E=0.78, p=.224)$. Pairwise tests showed one significant difference, between the Self- 


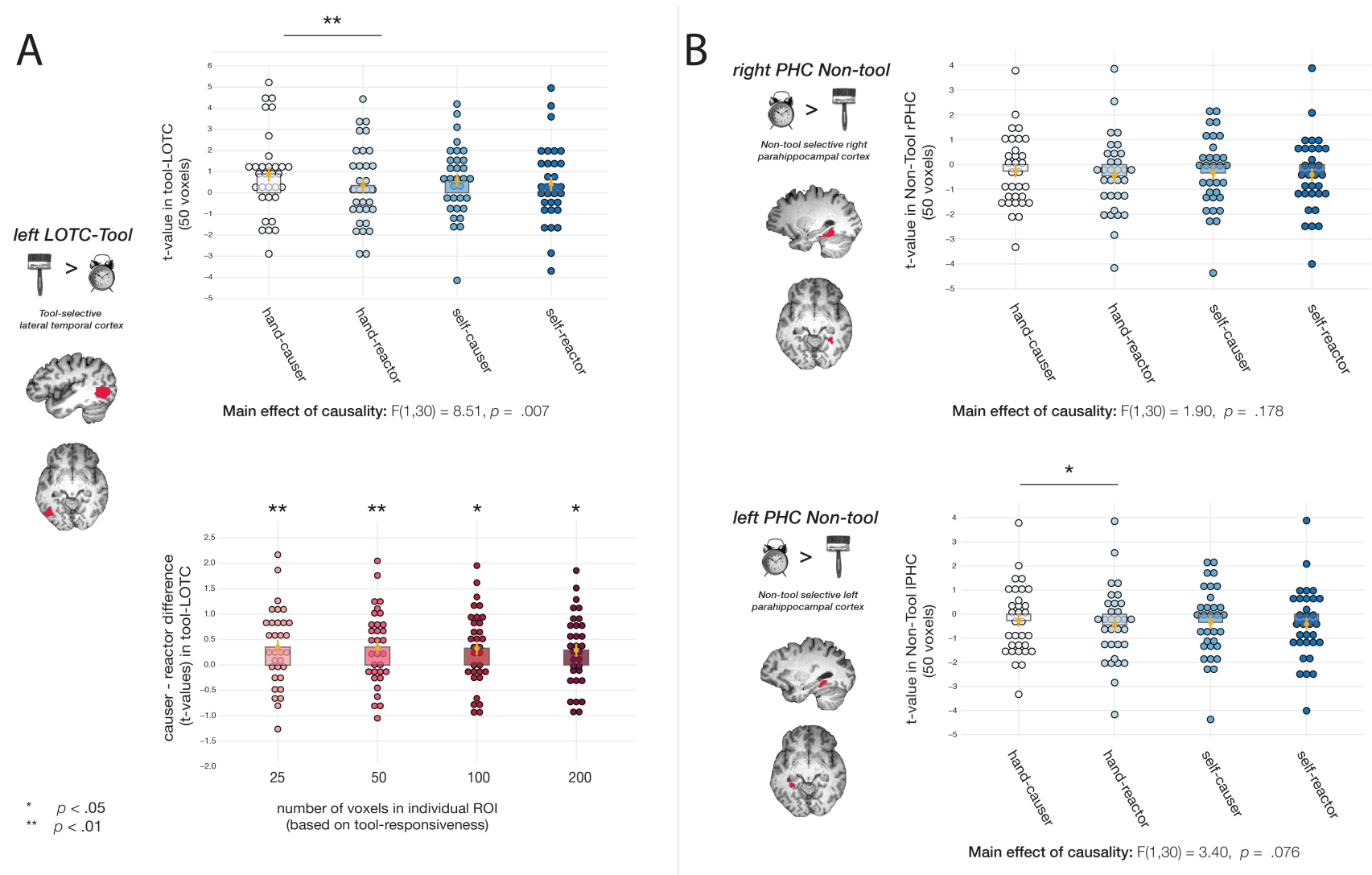

Figure 3. Figure 3. A. Results in Tool-selective left LOTC. Left: the significant group cluster defined using the contrast Tools $>$ Non-Tools in the localizer experiment, from which individual ROIs were selected. Top, $t$-values reflecting the activation in response to each of the Novel Object conditions relative to baseline, revealing a main effect of Causality and a significant pair-wise comparison between Hand-Causer and Hand-Reactor conditions. This is shown when left LOTC is defined using the top 50 voxels in each individual. Bottom, the overall Causer-Reactor difference as a function of the number of voxels in each individual ROI. B.Results in Non-Tool selective right PHC and left PHC, defined using the top 50 voxels in each individual. Left, the significant group clusters defined using the contrast Non-Tools $>$ Tools in the localizer experiment, from which individual ROIs were selected. Top, $t$-values reflecting the activation in response to each of the Novel Object conditions relative to baseline, in right PHC. There were no significant differences among conditions. Bottom, $t$-values reflecting the activation in response to each of the Novel Object conditions relative to baseline, in left PHC. There was a trend towards a main effect of causality and a significant difference between the Hand-Causer and Hand-Reactor conditions. $*=p<.05$.

Causer and Hand-Causer $(t(31)=2.21, p=.035)$, with Hand-Causer seen as more-tool like. No other effects were significant (all $p>.071$ ). While we had expected stronger condition differences in the perceptions of tool-likeness, it is likely that adults typically use a constellation of features to judge whether something should be called a tool, likely including canonical shape and transparency of physical mechanism (Bechtel, Jeschonek, \& Pauen, 2013; Malt \& Johnson, 1992).

\subsection{Tool and Non-Tool Selective Areas}

Category localizer data were used to compare activation in response to familiar Tools vs Non-Tools. Consistently with past findings, areas in left LOTC and left IPS were significantly more responsive to Tools than Non-Tools; left LOTC is shown in Figure 3 and left IPS in Figure S1. We defined individual ROIs using each participant's top $n$ tool-selective voxels within these significant grouplevel areas and assessed the response in each ROI to the different conditions in the main experiment; $n$ was initially set to 200 per our preregistration. Block one training accuracy was used as a within-subject regressor of non-interest.

In LOTC, a 2 (Movement Type: Self vs Hand) $x$ 2 (Causality: Causer vs Reactor) ANOVA revealed a main effect of Causality $(F(1,30)=6.15, M S E=3.05, p=$ .019 , partial $\left.\eta^{2}=0.170\right)$, such that activation in LOTC was higher for Causer objects than Reactor objects (Self-Causer: $M=0.61, S D=1.48$; Hand-Causer: $M=$ $0.80, S D=1.75$; Self-Reactor: $M=0.44, S D=1.64$; HandReactor: $M=0.38, S D=1.58)$. There was no main effect of Movement Type $(F(1,30)=0.00, M S E=0.00, p=.968)$ and no interaction $(F(1,30)=1.05, M S E=0.51, p=.313)$. Planned comparisons between Causer and Reactor within Movement Type revealed no effect of Causality in 
Table 1 Results from Movement $\times$ Causality ANOVA in Tool-Selective Areas

\begin{tabular}{|c|c|c|c|c|c|c|c|c|c|}
\hline \multicolumn{10}{|c|}{ LOTC } \\
\hline & $\begin{array}{l}\text { Self-Causer } \\
M(S D)\end{array}$ & $\begin{array}{c}\text { Self-Reactor } \\
M(S D)\end{array}$ & $\begin{array}{c}\text { Hand-Causer } \\
M(S D)\end{array}$ & $\begin{array}{c}\text { Hand-Reactor } \\
M(S D)\end{array}$ & $\begin{array}{c}\text { Causality } \\
\text { Main Effect }\end{array}$ & $\begin{array}{l}\text { Movement } \\
\text { Main Effect }\end{array}$ & $\begin{array}{c}\text { Movement } \times \text { Causality } \\
\text { Interaction }\end{array}$ & $\begin{array}{c}\text { Causality Within Self } \\
\text { Simple Effect }\end{array}$ & $\begin{array}{c}\text { Causality Within Hand } \\
\text { Simple Effect }\end{array}$ \\
\hline 25 voxels & $0.55(1.69)$ & $0.40(1.84)$ & $0.85(2.02)$ & $0.29(1.91)$ & $\begin{array}{l}F=8.20 \\
p=.008 \\
\eta_{p}^{2}=0.215\end{array}$ & $\begin{array}{l}F=0.05 \\
p=.817\end{array}$ & $\begin{array}{l}F=2.68 \\
p=.112\end{array}$ & $\begin{array}{l}F=0.87 \\
p=.360\end{array}$ & $\begin{array}{l}F=11.55 \\
p=.002 \\
\eta_{p}^{2}=0.278\end{array}$ \\
\hline 50 voxels & $0.59(1.70)$ & $0.42(1.87)$ & $0.89(1.97)$ & $0.35(1.88)$ & $\begin{array}{l}F=8.51 \\
p=.007 \\
\eta_{p}^{2}=0.221\end{array}$ & $\begin{array}{l}F=0.13 \\
p=.723\end{array}$ & $\begin{array}{l}F=2.38 \\
p=.134\end{array}$ & $\begin{array}{l}F=1.08 \\
p=.306\end{array}$ & $\begin{array}{l}F=11.62 \\
p=.002 \\
\eta_{p}^{2}=0.279\end{array}$ \\
\hline 100 voxels & $0.58(1.66)$ & $0.41(1.79)$ & $0.84(1.91)$ & $0.35(1.78)$ & $\begin{array}{l}F=7.36 \\
p=.011 \\
\eta_{p}^{2}=0.197\end{array}$ & $\begin{array}{l}F=0.05 \\
p=.826\end{array}$ & $\begin{array}{l}F=1.79 \\
p=.191\end{array}$ & $\begin{array}{l}F=1.19 \\
p=.283\end{array}$ & $\begin{array}{l}F=9.90 \\
p=.004 \\
\eta_{p}^{2}=0.248\end{array}$ \\
\hline 200 voxels & $0.61(1.48)$ & $0.44(1.64)$ & $0.80(1.75)$ & $0.38(1.58)$ & $\begin{array}{l}F=6.15 \\
p=.019 \\
\eta_{p}^{2}=0.170\end{array}$ & $\begin{array}{l}F=0.00 \\
p=.968\end{array}$ & $\begin{array}{l}F=1.05 \\
p=.313\end{array}$ & $\begin{array}{l}F=1.24 \\
p=.274\end{array}$ & $\begin{array}{l}F=7.67 \\
p=.010 \\
\eta_{p}^{2}=0.204\end{array}$ \\
\hline & & & & & & PS & & & \\
\hline & $\begin{array}{c}\text { Self-Causer } \\
M(S D)\end{array}$ & $\begin{array}{c}\text { Self-Reactor } \\
M(S D)\end{array}$ & $\begin{array}{c}\text { Hand-Causer } \\
M(S D)\end{array}$ & $\begin{array}{c}\text { Hand-Reactor } \\
M(S D)\end{array}$ & $\begin{array}{c}\text { Causality } \\
\text { Main Effect }\end{array}$ & $\begin{array}{c}\text { Movement } \\
\text { Main Effect }\end{array}$ & $\begin{array}{c}\text { Movement } \times \text { Causality } \\
\text { Interaction }\end{array}$ & $\begin{array}{c}\text { Causality Within Self } \\
\text { Simple Effect }\end{array}$ & $\begin{array}{c}\text { Causality Within Hand } \\
\text { Simple Effect }\end{array}$ \\
\hline 25 voxels & $0.12(2.01)$ & $0.19(2.03)$ & $0.34(2.21)$ & $0.13(2.38)$ & $\begin{array}{l}F=0.58 \\
p=.454\end{array}$ & $\begin{array}{l}F=0.25 \\
p=.619\end{array}$ & $\begin{array}{l}F=1.81 \\
p=.189\end{array}$ & $\begin{array}{l}F=0.22 \\
p=.646\end{array}$ & $\begin{array}{l}F=2.35 \\
p=.136\end{array}$ \\
\hline 50 voxels & $0.18(2.01)$ & $0.20(1.97)$ & $0.39(2.15)$ & $0.20(2.31)$ & $\begin{array}{l}F=0.80 \\
p=.379\end{array}$ & $\begin{array}{l}F=0.63 \\
p=.435\end{array}$ & $\begin{array}{l}F=1.15 \\
p=.293\end{array}$ & $\begin{array}{l}F=0.03 \\
p=.861\end{array}$ & $\begin{array}{l}F=2.03 \\
p=.164\end{array}$ \\
\hline 100 voxels & $0.21(1.92)$ & $0.19(1.88)$ & $0.38(2.04)$ & $0.20(2.18)$ & $\begin{array}{l}F=1.62 \\
p=.213\end{array}$ & $\begin{array}{l}F=0.45 \\
p=.508\end{array}$ & $\begin{array}{l}F=0.70 \\
p=.410\end{array}$ & $\begin{array}{l}F=0.04 \\
p=.849\end{array}$ & $\begin{array}{l}F=2.08 \\
p=.159\end{array}$ \\
\hline 200 voxels & $0.13(1.78)$ & $0.10(1.79)$ & $0.27(1.85)$ & $0.02(1.90)$ & $\begin{array}{l}F=2.94 \\
p=.097\end{array}$ & $\begin{array}{l}F=0.01 \\
p=.930\end{array}$ & $\begin{array}{l}F=1.21 \\
p=.279\end{array}$ & $\begin{array}{l}F=0.07 \\
p=.797\end{array}$ & $\begin{array}{l}F=3.60 \\
p=.067\end{array}$ \\
\hline
\end{tabular}

Note: all ANOVA degrees of freedom are $(1,30)$

the Self-mover objects $(F(1,30)=1.24, M S E=0.45, p=$ $.274)$, but a significant effect of Causality in the Handmoved objects $(F(1,30)=7.67, M S E=3.55, p=.010$, partial $\left.\eta^{2}=0.204\right)$.

We next investigated whether the Causer vs Reactor effect was observed in the most highly tool-selective voxels. We varied $n$ by taking either the 100,50 , or 25 most tool-selective voxels for each individual LOTC. Results across values of $n$ are displayed in Table 1 and Figure 3, which show that the main effect of Causality remained robustly significant when restricting analyses to these smaller, more tool-selective ROIs (100 voxels: $F(1,30)=$ 7.36, $M S E=3.88, p=.011$, partial $\eta^{2}=0.197 ; 50$ voxels: $F(1,30)=8.51, M S E=4.45, p=.007$, partial $\eta^{2}=0.221$; 25 voxels: $F(1,30)=8.20, M S E=4.53, p=.008$, partial $\left.\eta^{2}=0.215\right)$. No other effects were observed within these ROIs (all $p>.11$ ).

In left IPS, we did not find differences between the novel object conditions at $n=200$ (Self-Causer: $M=0.13, S D=1.78$; Hand-Causer: $M=$
$0.27, S D=1.85$; Self-Reactor: $M=0.10, S D=1.79$; HandReactor: $M=0.02, S D=1.90)$. A $2 \times 2$ ANOVA revealed no main effect of Causality $(F(1,30)=2.94, M S E=$ $0.65, p=.097)$, no main effect of Movement Type $(F(1,30)=0.008, M S E=0.00, p=.930)$, and no interaction $(F(1,30)=1.21, M S E=0.39, p=.279)$. Planned comparisons between Causer and Reactor within Movement Type revealed no effect of Causality in the Self-moving objects $(F(1,30)=0.07, M S E=0.02, p=.797)$ nor in the Hand-moving objects $(F(1,30)=3.60, M S E=1.09, p=$ $.067)$. This pattern of findings was consistent across values of $n$; detailed results are shown in Table 1.

Non-Tool-selective ROIs included areas in the left and right parahippocampal cortex (rPHC and $\mathrm{PHC}$ ); these areas and results across settings of $\mathrm{n}$ are shown in Table 2 and Figure 3. In right PHC with $n=200$, we found similar levels of activation across conditions (Self-Causer: $M=-0.31, S D=1.29$; Hand-Causer: $M=-0.19, S D=1.26$; Self-Reactor: $M=$ $-0.42, S D=1.31$; Hand-Reactor: $M=-0.42, S D=1.33)$. 
Table 2 Results from Movement $\times$ Causality ANOVA in Non-Tool-Selective Areas

\begin{tabular}{|c|c|c|c|c|c|c|c|c|c|}
\hline \multicolumn{10}{|c|}{ rPHC } \\
\hline & $\begin{array}{l}\text { Self-Causer } \\
M(S D)\end{array}$ & $\begin{array}{l}\text { Self-Reactor } \\
M(S D)\end{array}$ & $\begin{array}{l}\text { Hand-Causer } \\
M(S D)\end{array}$ & $\begin{array}{l}\text { Hand-Reactor } \\
\qquad M(S D)\end{array}$ & $\begin{array}{c}\text { Causality } \\
\text { Main Effect }\end{array}$ & $\begin{array}{l}\text { Movement } \\
\text { Main Effect }\end{array}$ & $\begin{array}{c}\text { Movement } \times \text { Causality } \\
\text { Interaction }\end{array}$ & $\begin{array}{l}\text { Causality Within Self } \\
\text { Simple Effect }\end{array}$ & $\begin{array}{c}\text { Causality Within Hand } \\
\text { Simple Effect }\end{array}$ \\
\hline 25 voxels & $-0.30(1.48)$ & $-0.35(1.53)$ & $-0.26(1.50)$ & $-0.40(1.49)$ & $\begin{array}{l}F=0.01 \\
p=.939\end{array}$ & $\begin{array}{l}F=0.17 \\
p=.686\end{array}$ & $\begin{array}{l}F=0.12 \\
p=.730\end{array}$ & $\begin{array}{l}F=0.10 \\
p=.752\end{array}$ & $\begin{array}{l}F=1.19 \\
p=.284\end{array}$ \\
\hline 50 voxels & $-0.34(1.47)$ & $-0.42(1.51)$ & $-0.26(1.46)$ & $-0.45(1.55)$ & $\begin{array}{l}F=1.90 \\
p=.178\end{array}$ & $\begin{array}{l}F=0.01 \\
p=.923\end{array}$ & $\begin{array}{l}F=0.18 \\
p=.672\end{array}$ & $\begin{array}{l}F=0.22 \\
p=.644\end{array}$ & $\begin{array}{l}F=1.71 \\
p=.201\end{array}$ \\
\hline 100 voxels & $-0.33(1.39)$ & $-0.39(1.40)$ & $-0.25(1.34)$ & $-0.44(1.46)$ & $\begin{array}{l}F=2.12 \\
p=.156\end{array}$ & $\begin{array}{l}F=0.06 \\
p=.803\end{array}$ & $\begin{array}{l}F=0.30 \\
p=.589\end{array}$ & $\begin{array}{l}F=0.18 \\
p=.676\end{array}$ & $\begin{array}{l}F=2.02 \\
p=.166\end{array}$ \\
\hline 200 voxels & $-0.31(1.29)$ & $-0.42(1.31)$ & $-0.19(1.26)$ & $-0.42(1.33)$ & $\begin{array}{l}F=3.74 \\
p=.063\end{array}$ & $\begin{array}{l}F=0.02 \\
p=.890\end{array}$ & $\begin{array}{l}F=0.29 \\
p=.593\end{array}$ & $\begin{array}{l}F=0.67 \\
p=.420\end{array}$ & $\begin{array}{l}F=2.90 \\
p=.099\end{array}$ \\
\hline \multicolumn{10}{|c|}{ IPHC } \\
\hline & $\begin{array}{c}\text { Self-Causer } \\
M(S D)\end{array}$ & $\begin{array}{c}\text { Self-Reactor } \\
M(S D)\end{array}$ & $\begin{array}{c}\text { Hand-Causer } \\
M(S D)\end{array}$ & $\begin{array}{c}\text { Hand-Reactor } \\
M(S D)\end{array}$ & $\begin{array}{c}\text { Causality } \\
\text { Main Effect }\end{array}$ & $\begin{array}{c}\text { Movement } \\
\text { Main Effect }\end{array}$ & $\begin{array}{c}\text { Movement } \times \text { Causality } \\
\text { Interaction }\end{array}$ & $\begin{array}{l}\text { Causality Within Self } \\
\text { Simple Effect }\end{array}$ & $\begin{array}{c}\text { Causality Within Hand } \\
\text { Simple Effect }\end{array}$ \\
\hline 25 voxels & $-0.44(1.41)$ & $-0.57(1.26)$ & $-0.27(1.35)$ & $-0.59(1.37)$ & $\begin{array}{l}F=4.35 \\
p=.046 \\
\eta_{p}^{2}=0.130\end{array}$ & $\begin{array}{l}F=0.56 \\
p=.460\end{array}$ & $\begin{array}{l}F=0.64 \\
p=.430\end{array}$ & $\begin{array}{l}F=0.60 \\
p=.443\end{array}$ & $\begin{array}{l}F=4.89 \\
p=.035 \\
\eta_{p}^{2}=0.144\end{array}$ \\
\hline 50 voxels & $-0.54(1.34)$ & $-0.64(1.25)$ & $-0.43(1.17)$ & $-0.70(1.21)$ & $\begin{array}{l}F=3.40 \\
p=.076\end{array}$ & $\begin{array}{l}F=0.07 \\
p=.795\end{array}$ & $\begin{array}{l}F=0.62 \\
p=.438\end{array}$ & $\begin{array}{l}F=0.40 \\
p=.531\end{array}$ & $\begin{array}{l}F=4.29 \\
p=.047 \\
\eta_{p}^{2}=0.129\end{array}$ \\
\hline
\end{tabular}

Note: all ANOVA degrees of freedom are $(1,30)$ in rPHC and $(1,29)$ in IPHC

A $2 \times 2$ ANOVA revealed a marginal main effect of Causality $(F(1,30)=3.74, M S E=0.89, p=.063$, partial $\left.\eta^{2}=0.111\right)$, no main effect of Movement Type $(F(1,30)=0.02, M S E=0.01, p=.890)$, and no interaction $(F(1,30)=0.29, M S E=0.13, p=.593)$. Comparisons between Causer and Reactor within Movement Type revealed no effect of Causality in the Self-moving objects $(F(1,30)=0.67, M S E=0.15, p=.420)$, nor in the Hand-moving objects $(F(1,30)=2.90, M S E=1.09, p=$ .099). Table 2 shows that at more selective values of $n$, there were again no significant or marginal effects.

We next compared right $\mathrm{PHC}$ with Tool-selective LOTC directly. A 2 (ROI: LOTC vs $\mathrm{rPHC}) \times 2$ (Causality) $\times 2$ (Movement Type) ANOVA was performed at each level of $n$, with results shown in Figure 4 and Table 3 . At $n=25$, the most selective analysis, we found a main effect of ROI $(F(1,31)=6.75, M S E=46.03, p=$ .014 , partial $\left.\eta^{2}=0.179\right)$, indicating greater activation in the LOTC overall, and a main effect of Causality $\left(F(1,30)=5.18, M S E=3.60, p=.030\right.$, partial $\left.\eta^{2}=0.147\right)$, indicating overall greater activation to Causers than Reactors. Critically, there was a significant ROI $\times$ Causality interaction $(F(1,31)=6.31, M S E=1.08, p=.017$, partial $\left.\eta^{2}=0.169\right)$, indicating a greater effect of Causality in LOTC than in rPHC. Complete results in Table 3 reveal significant ROI $\times$ Causality interactions at $n=50$ and 100 but not 200; thus, this effect may be limited to relatively more Tool-selective and Non-Tool selective voxels. Overall, these findings suggest that preferential responses to Causal novel objects are seen more reliably in Tool-selective voxels than Non-Tool selective ones.

The Non-Tool selective left PHC group level cluster (Figure 3) was only 60 voxels in size, and thus less strongly selective than the right PHC for NonTools (its $p$-value is higher according to our clustersize based statistics). At $n=25$, we found significant effects among the novel object conditions in the left PHC (Self-Causer: $M=-0.44, S D=1.41$; Hand-Causer: $M=-0.27, S D=1.35$; Self-Reactor: $M=$ $-0.57, S D=1.26$; Hand-Reactor: $M=-0.59, S D=1.37$ ) as shown in a $2 \times 2$ ANOVA, which revealed a main effect of Causality $(F(1,29)=4.35, M S E=1.68, p=.046$, partial $\eta^{2}=0.130$ ), no main effect of Movement Type $(F(1,29)=0.56, M S E=0.23, p=.460)$, and no interaction $(F(1,29)=0.64, M S E=0.26, p=.430)$.

Comparisons between Causer and Reactor within Movement Type revealed no effect of Causality in the Self-moving objects $(F(1,29)=0.60, M S E=0.26, p=$ .443), but there was a main effect of Causality in the Hand-moving objects $(F(1,29)=4.89, M S E=1.69, p=$ .035 , partial $\left.\eta^{2}=0.144\right)$. There was no interaction with left LOTC, as tested by a 2 (ROI: LOTC vs left PHC) $\times 2$ (Causality) $\times 2$ (Movement Type) ANOVA . This instead revealed a main effect of ROI $(F(1,30)=$ 


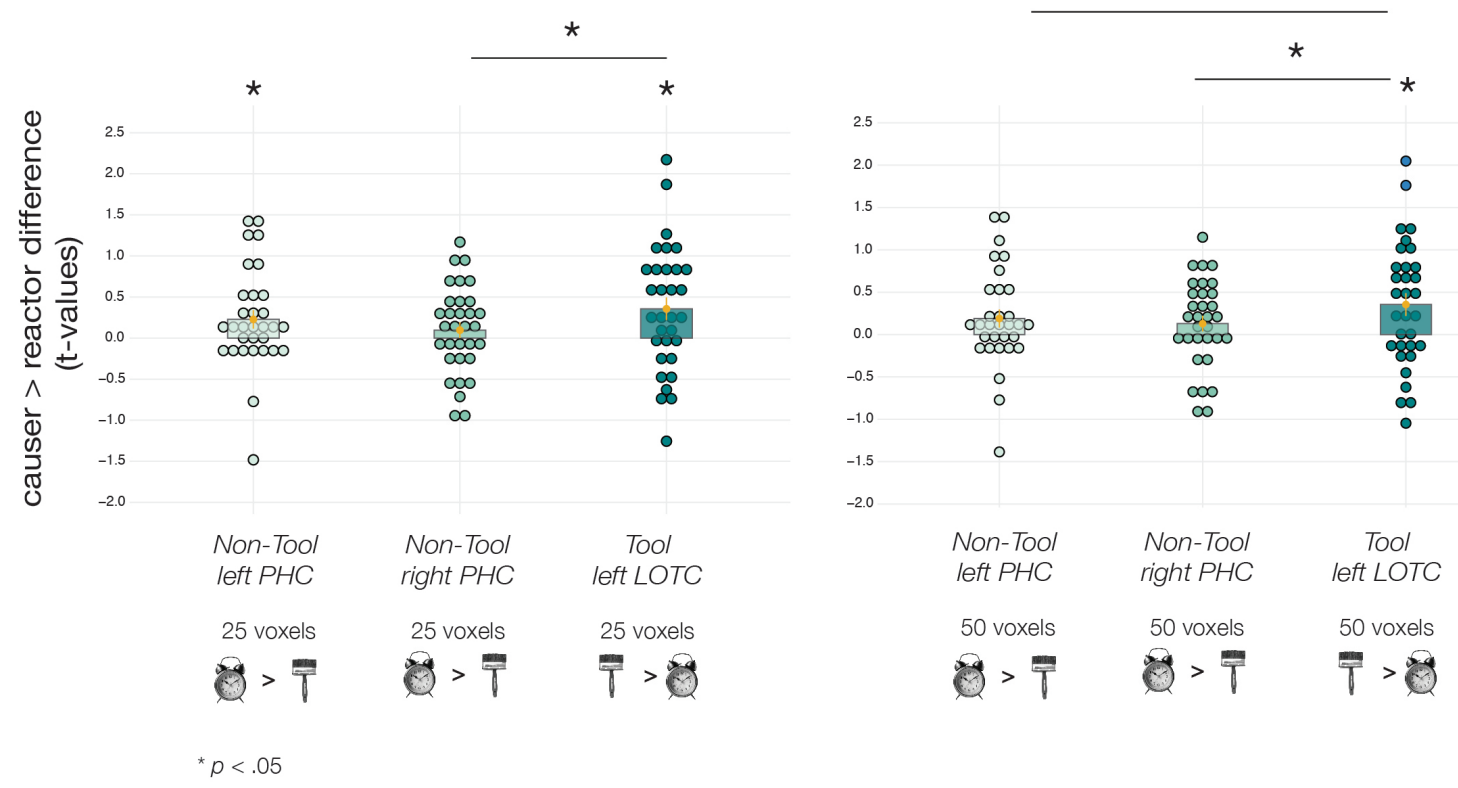

Figure 4. Figure 4. Main effect of Causality (Causer-Reactor mean difference in t-values) in the novel object conditions across three ROIs: Non-Tool Left PHC, Non-Tool Right PHC, and Tool Left LOTC. Left: results when ROIs are defined using the 25 most selective voxels in each individual. Right: results when ROIs are defined using the 50 most selective voxels in each individual. Results reveal a greater effect of Causality in Tool Left LOTC relative to Non-Tool Right PHC at both ROI sizes/selectivities, and a relative to Non-Tool Left PHC at 50 voxels. $*=p<.05$.

11.94, $M S E=65.13, p=.002$, partial $\left.\eta^{2}=0.285\right)$, indicating greater activation in the LOTC overall, and a main effect of Causality $(F(1,29)=7.34, M S E=6.01, p=.011$, partial $\eta^{2}=0.202$ ), such that there was overall greater activation to Causers than Reactors, but no other effects $(p>.159)$.

However, at $n=50$, the pattern changed, showing no significant main effect of Causality (Table 2; Figure 3 ) but an effect of Causality within the Hand-movers $\left(F(1,29)=4.29, M S E=1.27, p=.047\right.$, partial $\left.\eta^{2}=0.129\right)$. We also observed a significant ROI $\times$ Causality interaction with Tool-selective LOTC $(F(1,29)=4.42, M S E=$ $0.48, p=.044$, partial $\eta^{2}=0.128$; Table 3 , Figure 4 ). Thus, the effects in left PHC were not stable across voxel selection parameters. Nonetheless, there do appear to be some effects of causality in this area. Its weaker NonTool selectivity and partial sensitivity to Causality are likely related, and may be an outcome of its shared left lateralization with tool responses.

Neither of the occipital Non-Tool-selective ROIs (left OCC or right OCC) showed any significant or marginal effects in the novel object conditions and each of them interacted significantly with Tool-selective LOTC, at every setting of $n$ (see Table S1 and Table S2). Thus, effects of the novel object conditions appear to be limited to higher-level temporal areas.

\subsection{Tool and Hand Selective LOTC}

Prior research has reliably reported overlap between the response to tools and the response to hands in LOTC (Bracci et al., 2016, 2011, 2017; Bracci \& Peelen, 2013). This hand-and-tool selective area is preserved in those born without hands (Striem-Amit, Vannuscorps, \& Caramazza, 2017) and exhibits a stronger response to objects one acts "with" - such as canonical tools - than to objects one acts "on", such as musical instruments (Bracci \& Peelen, 2013). A response to both tools and hands may thus be an important predictor of voxels with a strong sensitivity to causality.

We used a conjunction analysis to define Hand-andTool selective LOTC (Hand-Tool LOTC), specifically by contrasting Tools $>$ Non-Tools and Hands $>$ Animals, then using the minimum statistic from these two contrasts to define the statistics for the conjunction. We selected the $n$ (25 and 50) most significant voxels in the conjunction statistic for each individual within a significant group cluster for the same analysis, identified in LOTC (Figure 5). We then probed the pattern of responses in this area to the novel object conditions.

A 2 (Movement Type: Self vs Hand) $\times 2$ (Causality: Causer vs Reactor) ANOVA with block one training accuracy as a regressor of non-interest revealed highly reliable effects of causality in these areas at $n=25$ 


\section{left LOTC hand \& tool} 50 voxels

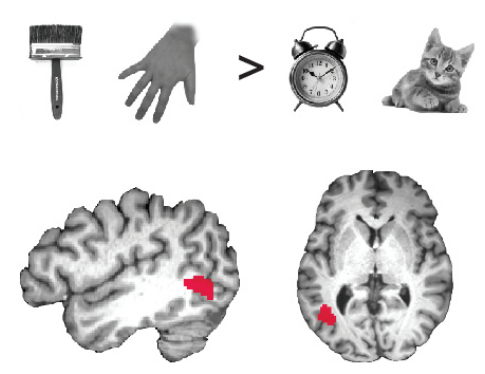

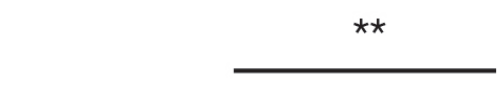

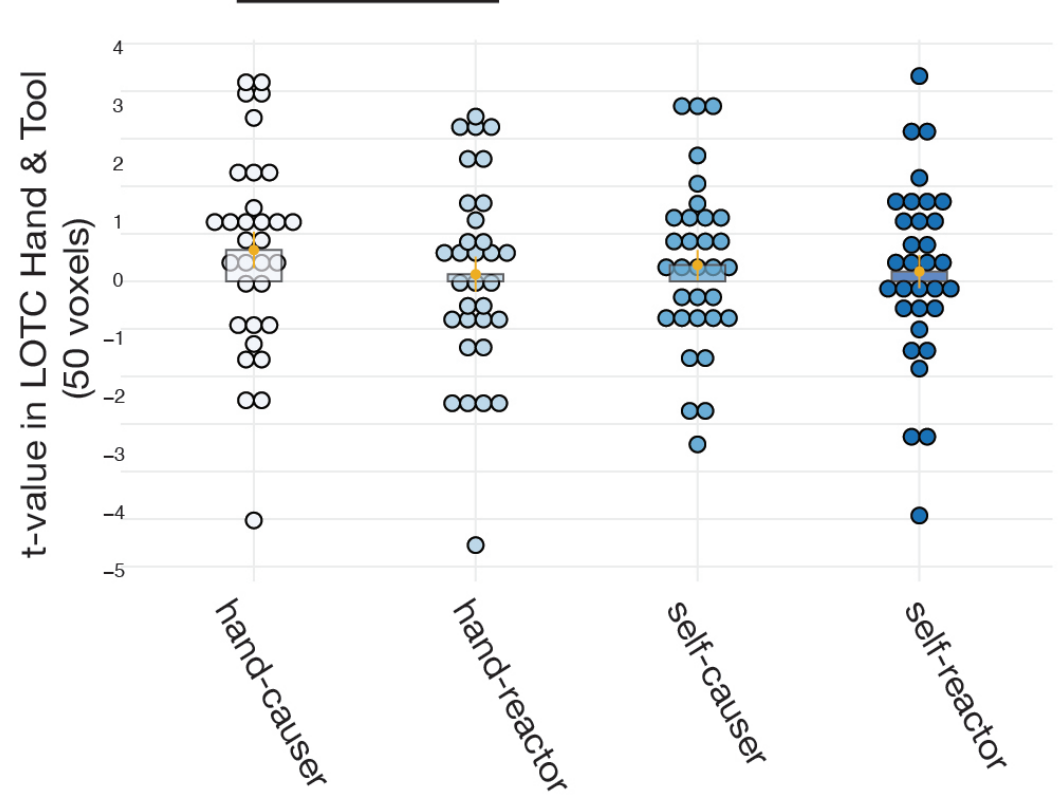

Main effect of causality: $F(1,30)=8.78 p=.006$

Figure 5. Figure 5. Results in Hand and Tool selective left LOTC, defined using the 50 most selective voxels in each individual. Left, the significant group cluster showing stronger responses to Tools and Hands relative to Non-Tools and Animals, from which individual ROIs were selected. Right, t-values reflecting the activation in response to each of the novel object conditions relative to baseline. Results show a main effect of Causality and a significantly stronger response to the Hand-Causer than the Hand-Reactor conditions. $* * p<.01$.

$\left(F(1,30)=9.50, M S E=4.43, p=.004\right.$, partial $\left.\eta^{2}=0.240\right)$ and $n=50(F(1,30)=8.78, M S E=3.86, p=.006$, partial $\left.\eta^{2}=0.226\right)$, such that activation in Hand-Tool LOTC was higher for Causers than Reactors $(n=25$ : Self-Causer: $M=0.37, S D=1.75$; Hand-Causer: $M=0.73, S D=2.11$; Self-Reactor: $M=0.24, S D=1.93$; Hand-Reactor: $M=$ $0.16, S D=2.08 ; n=50$ : Self-Causer: $M=0.34, S D=1.77$; Hand-Causer: $\mathrm{M}=0.66, \mathrm{SD}=2.13$; Self-Reactor: $M=$ $0.21, S D=1.93$; Hand-Reactor: $M=0.15, S D=2.06)$. No other effects were observed in these ROIs $(p>.093)$.

Analyses restricted within Movement-Type revealed an effect of Causality within the Hand-moving objects at $n=25(F(1,30)=13.72, M S E=6.37, p=.001$, partial $\left.\eta^{2}=0.314\right)$ and $n=50(F(1,30)=12.37, M S E=5.31, p=$ .001 , partial $\left.\eta^{2}=0.292\right)$. This effect was not observed in the Self-moving objects $(p>.369)$. Similar to the findings in Tool-LOTC, causality effects in Hand-Tool LOTC were stronger than in right $\mathrm{PHC}$ but not left PHC (Table 4).

For right $\mathrm{PHC}$ at $n=25$, we found a main effect of ROI $(F(1,31)=4.68, M S E=31.50, p=.038$, partial $\left.\eta^{2}=0.131\right)$, indicating greater activation in Hand-Tool LOTC overall, as well as a main effect of Causality
$\left(F(1,30)=5.55, M S E=3.54, p=.025\right.$, partial $\left.\eta^{2}=0.156\right)$. We also observed a significant ROI $\times$ Causality interaction $(F(1,31)=6.41, M S E=1.00, p=.017$, partial $\left.\eta^{2}=0.171\right)$, indicating a greater effect of Causality in Hand-Tool LOTC than in rPHC. No other significant effects were observed $(p>.183)$.

For left PHC at $n=25$, we also found a main effect of ROI $(F(1,30)=8.03, M S E=43.19, p=.008$, partial $\left.\eta^{2}=0.211\right)$, indicating greater activation in HandTool LOTC overall, as well as a main effect of Causality $\left(F(1,29)=8.36, M S E=6.10, p=.007\right.$, partial $\left.\eta^{2}=0.224\right)$. However, we found no significant ROI $\times$ Causality interaction $(F(1,30)=2.05, M S E=0.297, p=.163)$ and no other significant effects $(p>.194)$, Causality effects in Hand-Tool LOTC were not stronger than those in ToolLOTC (ROI - Causality interaction, $p>.40$ ). Outside of these ROIs, we did not find any areas with significantly differential responses to any of our novel object conditions when using whole-brain contrasts. 
Table 3 Results from ROI $\times$ Movement $\times$ Causality ANOVA

\begin{tabular}{|c|c|c|c|c|c|c|c|}
\hline \multicolumn{8}{|c|}{$\mathrm{rPHC} \times \mathrm{LOTC}$} \\
\hline & $\begin{array}{c}\mathrm{rPHC} \\
M(S D)\end{array}$ & $\begin{array}{l}\text { LOTC } \\
M(S D)\end{array}$ & $\begin{array}{c}\text { ROI } \\
\text { Main Effect }\end{array}$ & $\begin{array}{c}\text { Causality } \\
\text { Main Effect }\end{array}$ & $\begin{array}{l}\text { ROI } \times \text { Causality } \\
\text { Interaction }\end{array}$ & $\begin{array}{l}\text { ROI } \times \text { Movement } \\
\text { Interaction }\end{array}$ & $\begin{array}{c}\text { ROI } \times \text { Causality } \times \text { Movement } \\
\text { Interaction }\end{array}$ \\
\hline 25 voxels & $-0.33(1.48)$ & $0.52(1.86)$ & $\begin{array}{l}F=6.75 \\
p=.014 \\
\eta_{p}^{2}=0.179\end{array}$ & $\begin{array}{l}F=5.18 \\
p=0.030 \\
\eta_{p}^{2}=0.147\end{array}$ & $\begin{array}{l}F=6.31 \\
p=.017 \\
\eta_{p}^{2}=0.169\end{array}$ & $\begin{array}{l}F=0.60 \\
p=.444\end{array}$ & $\begin{array}{l}F=2.01 \\
p=.167\end{array}$ \\
\hline 50 voxels & $-0.37(1.48)$ & $0.56(1.85)$ & $\begin{array}{l}F=8.86 \\
p=.006 \\
\eta_{p}^{2}=0.222\end{array}$ & $\begin{array}{l}F=6.07 \\
p=.020 \\
\eta_{p}^{2}=0.168\end{array}$ & $\begin{array}{l}F=5.20 \\
p=.030 \\
\eta_{p}^{2}=0.144\end{array}$ & $\begin{array}{l}F=0.55 \\
p=.466\end{array}$ & $\begin{array}{l}F=1.49 \\
p=.232\end{array}$ \\
\hline 100 voxels & $-0.35(1.38)$ & $0.55(1.78)$ & $\begin{array}{l}F=11.19 \\
p=.002 \\
\eta_{p}^{2}=0.265\end{array}$ & $\begin{array}{l}F=5.56 \\
p=.025 \\
\eta_{p}^{2}=0.156\end{array}$ & $\begin{array}{l}F=4.58 \\
p=.040 \\
\eta_{p}^{2}=0.129\end{array}$ & $\begin{array}{l}F=0.50 \\
p=.486\end{array}$ & $\begin{array}{l}F=0.89 \\
p=.353\end{array}$ \\
\hline 200 voxels & $-0.34(1.29)$ & $0.56(1.60)$ & $\begin{array}{l}F=16.15 \\
p=.003 \\
\eta_{p}^{2}=0.343\end{array}$ & $\begin{array}{l}F=5.52 \\
p=.026 \\
\eta_{p}^{2}=0.155\end{array}$ & $\begin{array}{l}F=2.29 \\
p=.097\end{array}$ & $\begin{array}{l}F=0.02 \\
p=.889\end{array}$ & $\begin{array}{l}F=0.49 \\
p=.491\end{array}$ \\
\hline & & & & $\mathrm{IPHC}$ & $\times$ LOTC & & \\
\hline & $\begin{array}{l}\mathrm{lPHC} \\
M(S D)\end{array}$ & $\begin{array}{l}\text { LOTC } \\
M(S D)\end{array}$ & $\begin{array}{c}\text { ROI } \\
\text { Main Effect }\end{array}$ & $\begin{array}{l}\text { Causality } \\
\text { Main Effect }\end{array}$ & $\begin{array}{c}\text { ROI } \times \text { Causality } \\
\text { Interaction }\end{array}$ & $\begin{array}{l}\text { ROI } \times \text { Movement } \\
\text { Interaction }\end{array}$ & $\begin{array}{c}\text { ROI } \times \text { Causality } \times \text { Movement } \\
\text { Interaction }\end{array}$ \\
\hline 25 voxels & $-0.47(1.34)$ & $0.56(1.87)$ & $\begin{array}{l}F=11.94 \\
p=.002 \\
\eta_{p}^{2}=0.285\end{array}$ & $\begin{array}{l}F=7.34 \\
p=.011 \\
\eta_{p}^{2}=0.202\end{array}$ & $\begin{array}{l}F=2.09 \\
p=.159\end{array}$ & $\begin{array}{l}F=0.00 \\
p=.998\end{array}$ & $\begin{array}{l}F=0.84 \\
p=.367\end{array}$ \\
\hline 50 voxels & $-0.58(1.23)$ & $0.59(1.87)$ & $\begin{array}{l}F=16.86 \\
p<.001 \\
\eta_{p}^{2}=0.360\end{array}$ & $\begin{array}{l}F=6.71 \\
p=.015 \\
\eta_{p}^{2}=0.188\end{array}$ & $\begin{array}{l}F=4.42 \\
p=.044 \\
\eta_{p}^{2}=0.128\end{array}$ & $\begin{array}{l}F=0.35 \\
p=.560\end{array}$ & $\begin{array}{l}F=0.74 \\
p=.395\end{array}$ \\
\hline
\end{tabular}

Note: all ANOVA degrees of freedom are $(1,31)$ in $\mathrm{rPHC}$ and $(1,30)$ in $\mathrm{PHC}$

\subsection{Ventral Stream Preference Modeling}

The above pattern of findings suggests that areas with strong Tool-selectivity and Hand-selectivity also exhibit stronger responses to novel Causer objects than Reactor objects. This appears less the case in areas or voxels with weaker or other category preferences, painting an overall picture in which there is a relationship across the temporal lobe between a preference for real-world categories and a preference to a certain pattern of event relations, as captured in our novel object conditions. We tested this idea more directly by taking all IT ventral stream voxels (separately in each hemisphere) and measuring the correlation between the responses to real-world objects and the responses to the novel object conditions. We tested this by creating a within-participant regression model in which we predicted the Causer-Reactor response difference across ventral stream voxels as a function of how those voxels responded to each of the four real-world object categories during the localizer.

First, we found that in both hemispheres, the responses to Hands and Tools were themselves highly correlated. In left IT, Hand and Tool responses exhibited a mean correlation of $r=.840$. A fisher's Z transform of individual $r$ values was significantly above $0(M=$ $1.263, S D=0.235, t(31)=30.417, p<.001)$. In right IT, the mean Hand-Tool correlation was $r=.817$, and fisher's $\mathrm{Z}$ was again significantly above $0(M=1.204, S D=$ $0.263, t(31)=25.93, p<.001)$. This pattern of results is itself striking as it shows that Hands and Tools have remarkably similar responses across the full extent of IT cortex, beyond the local overlap in their peak responses. This is particularly notable in the right hemisphere, where no areas showed selective responses to Tools. The 
A

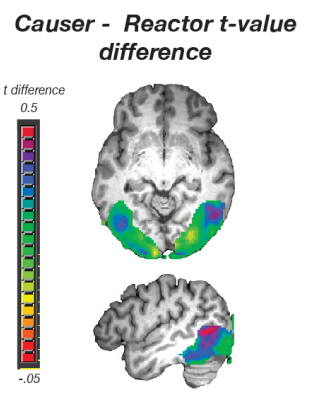

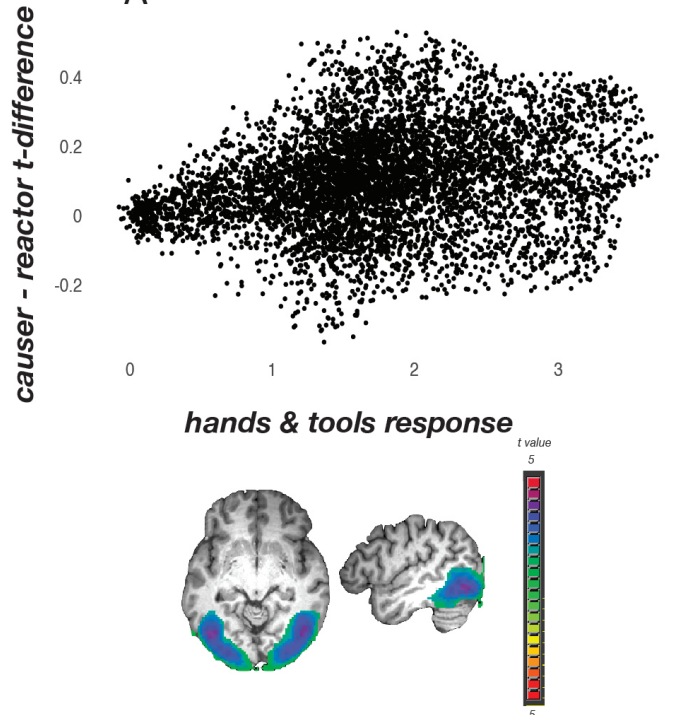

B
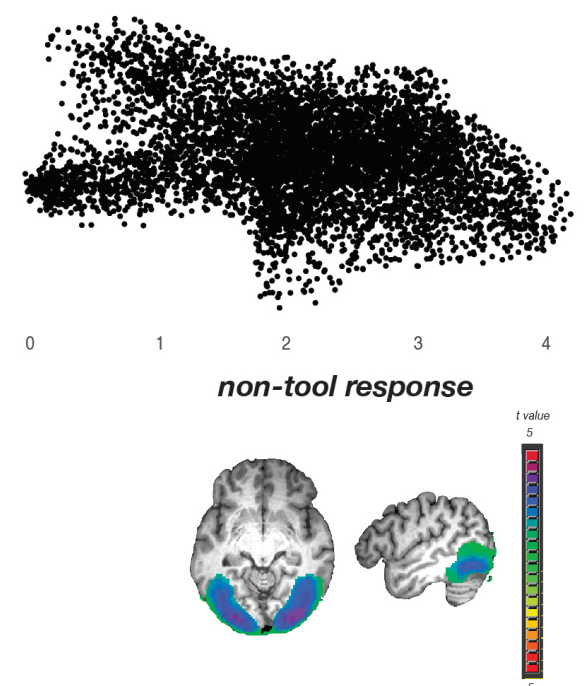

Figure 6. Figure 6. Results of the ventral stream preference analysis. Left: main effect of Causality ( $t$-value difference between Causers and Reactors) within the ventral stream mask. Bottom, the Hands \& Tools and Non-Tools response within the ventral stream mask. Scatterplot A shows the magnitude of each voxel's Causer-Reactor contrast as a function of its response to the Hands \& Tools average response. Scatterplot $\mathbf{B}$ shows the Causer-Reactor difference as a function of the Non-Tool response.

Hand-Tool correlation in the right and left IT cortices was not significantly different $(p=.120)$. For subsequent linear modeling, we averaged the Hand and Tool responses due to their strong collinearity.

To test the relationship between category preference and the Causer-Reactor difference, we ran withinparticipant linear regression to predict the CauserReactor difference in each voxel on the basis of those voxels' response to Animals, Non-Tools, and the Hands and Tools average, then compared the beta coefficients of these predictors across participants.

In left IT, we found that Hand-Tool responses were significantly predictive of the Causer-Reactor difference, $M=0.0725, S D=0.167, t(31)=2.460, p=.0197$, CI [ 0.0124, 0.133],$d=0.442$. Animal responses were not significantly predictive, $M=-0.009, S D=0.171, p=.772$, but were not significantly less predictive than Hand and Tool responses $(p=.124)$. Non-Tool responses approached significance in the reverse direction, $M=$ $-0.051, S D=0.162, t(31)=-1.777$, CI [-0.109,0.007], $p=$ $.085, d=0.319$, indicating that if anything, they predicted a stronger response to Reactors than Causers. As such, Non-Tool coefficients were significantly lower than Hand-Tool coefficients; $t(31)=2.496, \mathrm{CI}=[0.023$, $0.224], p=.018, d=0.448$. This confirms that the CauserReactor effect was significantly stronger in Hand and Tool preferring voxels than Non-Tool preferring voxels, as found in the ROI analyses.

In right IT, we found a similar pattern. The strength of Hand-Tool responses significantly predicted the Causer-
Reactor difference, $M=0.086, S D=0.434, t(31)=2.42$, $\mathrm{CE}[0.0135,0.159] p=.022, d=0.434$. Animal responses were not significantly predictive, $M=-0.001, S D=$ $0.214, p=.0989$, but not differently from the HandTool predictor $(p=.204)$. Non-Tool responses were significantly predictive in the reverse direction, $M=$ $-0.068, S D=0.152, t(31)=-2.55$, CI $[-0.123,-0.0138] p=$ $.016, d=0.459$, and were significantly different from the Hand-Tool coefficients, $t(31)=3.118, \mathrm{CI}=[0.053,0.256]$, $p=.004, d=0.560)$. Thus, the interaction between Tool and Non-Tool predictors remained strong in both hemispheres of the ventral stream, despite the absence of focal regions of Tool-selectivity in the right hemisphere. Results collapsing across the hemispheres are shown in Figure 6. These findings overall support the conclusion that there is a reliable relationship between categoryselective responses and the response to Causers and Reactors, with Tools/Hands and Non-Tools following a distinct pattern across bilateral IT cortex, such that Tool and Hand preferring voxels show a stronger preference to Causer vs Reactor objects.

\subsection{Follow-Up Experiment}

A follow-up experiment with ten participants was run to rule out an alternative possible explanation of our results. In the retrieval phase of main study, participants were encouraged to recall the event sequence associated with each object. If they visualized this sequence in its typical order, they may have visualized the first part of 
the event more reliably than the second (for example, if they ran out of time). In this case, stronger responses to the Causer objects than the Reactor objects in LOTC could reflect an overall preference to object or hand movement events over ambient events. Even though both ambient and movement events are dynamic, LOTC responds more to tool motion relative to animate motion (Beauchamp et al., 2002) and it is not known how it would respond to our ambient event stimuli.

We thus scanned new participants with fMRI while they viewed the same animated event sequences directly, rather than retrieving them from memory. This allowed us to obtain the perceptual responses to viewing these stimuli. When contrasting ambient events with object-based movement events, we found a reliable preference for the ambient events over object or hand movements in Tool-selective LOTC at $n=25$ voxels: Ambient, $M=2.97, S D=1.76$; Object-Based Movement, $M=-2.07, S D=1.24 ; t(9)=5.65, p<.001$; and at $n$ $=50$ voxels: Ambient, $M=2.93, S D=1.62$; Object-Based Movement, $M=-2.06, S D=1.13 ; t(9)=6.03, p<.001$. In Hand-Tool LOTC at $n=25$ and at $n=50$, we saw very similar effects: $t(9)=5.71, p<.001$ and $t(9)=4.89, p<.001$. Altogether, this runs counter to the predictions of the alternative hypothesis we aimed to rule out. We speculate that the reason for the significant preference to the ambient events could be that they are vividly colored and often more dynamic than object-based movements.

We did not observe reliable differences between the perceptually presented Causer vs Reactor animated sequences in either Tool or Hand-Tool ROIs. While such effects could have been observed, we speculate that they were absent because all of these event sequences exhibit causal relations between two entities when viewed, and thus, always have both a Causer and a Reactor. In contrast, the retrieval task in the main experiment showed an isolated object that had reliably served either and only as a Causer or a Reactor. These results may suggest that LOTC responses to Causers could be elicited by either more canonical objects or more diverse stimuli like streams of stars.

\section{DISCUSSION}

Our findings support the hypothesis that preferential responses in tool-selective LOTC can be elicited by objects associated with an event structure typical of tools: those which exert an effect on the environment ("Causers") compared to those which react to events in the environment ("Reactors"), holding constant shape and motor experience. We trained participants to associate novel objects with animated sequences that varied in their event structure. Causer objects moved prior to the appearance of an ambient event while Reactor objects moved after such an event. We localized tool-LOTC by contrasting responses to familiar tool vs non-tool images and exam- ined this area for its responses to still images of the novel Causers and Reactors. Indeed, we found that tool-LOTC responded more strongly to Causers than Reactors, revealing that the associated structure of event relations is sufficient to drive selective responses in LOTC, over and above shape or motor experience. In contrast, this preference was absent and significantly weaker in right $\mathrm{PHC}$, an area preferring non-tools to tools. A data-driven analysis across the bilateral ventral stream confirmed that real-world category preferences were strongly predictive of a preference to Causers over Reactors, with Tool (and Hand) preferences positively predictive of a Causer preference and Non-Tool preferences negatively so. We thus suggest that domain-selective organization in the temporal lobe is partially reflective of the relational event structures characterizing their preferred domains.

This result is not well accounted by the view that specializations within the brain's systems for object knowledge are driven largely by differences in sensory modalities, an account in which selective responses to tools would be due to their greater association with visual motion or motor knowledge (Lambon-Ralph, Jefferies, Patterson, \& Rogers, 2017; Martin, 2007; Patterson, Nestor, \& Rogers, 2007). Neither can explain our effects, because our event sequence conditions varied only in their relational structure and yet, this was sufficient to drive differential responses in domain-selective systems. These preferential responses thus need not be driven by differences in sensory modalities or attributes.

In contrast, our findings are well aligned with research demonstrating the importance of causal and functional information in children's and adults' categorization of artifacts (Bechtel et al., 2013; Futó et al., 2010; Gopnik \& Sobel, 2000; Hernik \& Csibra, 2009; Keil, Smith, Simons, \& Levin, 1998; Kelemen \& Carey, 2007; Kemler Nelson et al., 2000; Lombrozo \& Rehder, 2012; Träuble \& Pauen, 2011; Truxaw et al., 2006; Yee, Drucker, \& ThompsonSchill, 2010; Yee, Huffstetler, \& Thompson-Schill, 2011) and work arguing more broadly that many concepts obtain meaning from relational structure (Carey, 2009; Chatterjee, 2008; Goodman, Tenenbaum, Griffiths, \& Feldman, 2012; Gopnik \& Meltzoff, 1997; Jones \& Love, 2007; Kemp, Tenenbaum, Niyogi, \& Griffiths, 2010; Markman \& Stilwell, 2001). We argue that such properties are equally important in the neural organization of object knowledge, providing one possible explanation for the preservation of tool-selective responses in congenitally blind individuals (Mahon et al., 2009, 2010; Mattioni et al., 2020; Peelen et al., 2013) and in those born without hands (Striem-Amit et al., 2018).

Behaviorally, we found that tool-likeness ratings were only partially sensitive to our manipulations of causal event structure, with the Hand-Causer condition eliciting stronger tool-likeness judgments than the Self-Causer, but no reliable differences with the Reactor conditions. This finding is in line with work showing that causal 
properties are used in combination with other properties for categorizing objects as tools (Bechtel, Jeschonek, \& Pauen, 2013; Malt \& Johnson, 1992). It is also possible that the use of the lexical label 'tool' in language is not perfectly aligned with the factors driving cortical organization of object representations. An important direction for future research is to understand how the factors of causal schema, motor experience, and shape interact to influence responses in the temporal cortex.

How functional and causal properties of objects come to be represented also remains an active area of research (Kelemen \& Carey, 2007; Liu, Brooks, \& Spelke, 2019; Schulz, Goodman, Tenenbaum, \& Jenkins, 2008; Schulz \& Gopnik, 2004; Waismeyer, Meltzoff, \& Gopnik, 2014). Here we operationalized objects' causal properties as ordered event relations whose structure was conditional on the particular object involved. We based this operationalization on our prior research investigating how adults judge an objects' causal properties (Leshinskaya \& Thompson-Schill, 2019). We found in that work that participants relied specifically on a hierarchical structure of event relations: they judged an object to cause an event so long as that event appeared contingently on the object's motion, but not if it simply occurred frequently in its presence. This allowed us to specify how causal schemas can be inferred from observational event experience and to formalize the differences between our conditions. As such, Causers and Reactors appeared equally often in the presence of the same ambient events, but those ambient events had different relations with the objects' movements. This manipulation of event relations was sufficient to drive differential responses in tool-LOTC, supporting a relational account of its response.

Our findings are relevant to theories of the function of LOTC and surrounding cortex. A closely related proposal suggests that LOTC is tuned to objects that extend the body, in that they are used with the hand/arm to affect another object or surface (Bracci \& Peelen 2013). Bracci and Peelen used a wide variety of familiar objects that had been rated how much they extend the body; items like forks, tennis rackets and combs had high ratings relative to items like doorknobs, books, and violins. These ratings were in turn strong predictors of the extent of LOTC activation in response to them, whereas ratings on motor association and graspability were not.

Our account is subtly different. Body extension specifies both that an object exerts a causal effect on its surroundings and that it is used physically by the body to achieve this. Our notion of causal influence is broader. These accounts thus lead to somewhat different, though not mutually exclusive, predictions. For our data, a body extension account would predict that the effect of causality would be strongest in hand-moved objects, an interaction we did not see robustly but for which we may have lacked power. In contrast, we would predict that some items categorized as low on body extension in Bracci and Peelen's study (such as light switches) would exhibit stronger responses in LOTC than items with less of a causal influence overall (e.g., books); however, their data did not separate such items explicitly. Future work could directly compare the influence of causal properties vs body extension in the response of LOTC.

In addition to our main findings, we also replicated the result that LOTC is preferentially activated not just by images of tools, but also of hands (Bracci et al., 2016, 2011, 2017; Striem-Amit et al., 2017) and found that this common area also exhibited a strong preference for novel Causer vs Reactor objects. We furthermore showed overlap between tools and hands beyond their peak responses, finding a highly correlated response to these categories across the entire ventral stream; the strength of this common response also correlated with the magnitude of the Causer vs Reactor difference. The reason for this spatial overlap and functional similarity remains a matter of debate. The body-extension account suggests that it is driven by the fact that tools and hands are functionally interrelated, in that the former extend the latter. A causal account would argue it is driven by the fact that tools and hands are both causally effective, and explains why novel Causers also engaged similar areas. This latter view might be supported by computational work showing that learning to visually identify hands is facilitated by tracking objects that are 'movers' of other objects (Ullman, Harari, \& Dorfman, 2012). Using this 'mover' principle to learn to visually recognize hands would naturally lead to grouping hands with tools in the visual recognition system, regardless of whether the objects act in concert with the hands or alone, as both are movers.

Nonetheless, both of these theories take event relations as critical aspects of the function of LOTC. In our recent theoretical work, we argue on the basis of neuropsychological and neuroimaging evidence that this broader region supports understanding how actions involve objects and how objects participate in actions, as both are intertwined in causal schemas and in neural space (Leshinskaya, Wurm, \& Caramazza, 2020).

On a broader view, event relations are important in domains beyond artifacts: knowledge about animate entities also involves how they interact and this is likewise reflected in neural specialization. Isik and colleagues (Isik, Koldewyn, Beeler, \& Kanwisher, 2017) found that in posterior superior temporal sulcus (a region important in social understanding) there was a preferential response to point-light walkers that interact relative to those that act independently, suggesting that this area is tuned, in part, to spatiotemporal relations. Relatedly, Abassi \& Papeo (2020) found that the extrastriate body area of the ventral stream responds more strongly to twobody dyads that are facing each other than those that are facing away, suggesting this area is tuned to configu- 
rations of bodies that are poised to interact. Together with such findings, our work reinforces the conclusion that relational information is an important part of the content and organization of domain-selective temporal areas.

\section{CONCLUSION}

Various theories have been proposed to explain the function of tool-selective LOTC. Observations that this area also responds to hands and that it responds in absence of shape information or visual experience have suggested a more complex pattern of selectivity than to specific visual features. While motor interaction experience also influences this response, such effects could be driven by either motor association or the learning of a causal schema regarding how objects influence their environment. Our findings suggest that a causal schema typical of tools - influencing other events rather than responding to them - is sufficient to drive selective responses in LOTC, over and above the particularities of shape and motor experience. More generally, we suggest that preferential responses to particular domains across the temporal lobe may reflect the relational event structures typical of those domains.

\section{ACKNOWLEDGEMENTS}

This work was supported by NIH grants R01DC015359 and R01DC015359 to S.L.T-S. This work was previously presented at the 2020 Annual Meeting of the Vision Sciences Society.

\section{REFERENCES}

Anzellotti, S., Mahon, B. Z., Schwarzbach, J., \& Caramazza, A. (2011). Differential activity for animals and manipulable objects in the anterior temporal lobes. Journal of Cognitive Neuroscience, 23(8), 2059-2067.

Beauchamp, M. S., Lee, K., Haxby, J. V, \& Martin, A. (2002). Parallel visual motion processing streams for manipulable objects and human movements. Neuron, 34, 149-159. Bechtel, S., Jeschonek, S., \& Pauen, S. (2013). How 24-month-olds form and transfer knowledge about tools: The role of perceptual, functional, causal, and feedback information. Journal of Experimental Child Psychology, 115(1), 163-179.

Bracci, S., Cavina-Pratesi, C., Connolly, J. D., \& Ietswaart, M. (2016). Representational content of occipitotemporal and parietal tool areas. Neuropsychologia, 84, 81-88.

Bracci, S., Cavina-Pratesi, C., Ietswaart, M., Caramazza, A., \& Peelen, M. V. (2011). Closely overlapping responses to tools and hands in left lateral occipitotemporal cortex. Journal of Neurophysiology, 10\%,
$1443-1456$.

Bracci, S., Daniels, N., \& Op de Beeck, H. P. (2017). Task context overrules object- and category-related representational content in the human parietal cortex. Cerebral Cortex, 27(1), 310-321.

Bracci, S., \& Peelen, M. V. (2013). Body and object effectors: The organization of object representations in high-level visual cortex reflects bodyobject interactions. Journal of Neuroscience, $33(46)$, 18247-18258.

Brambati, S. M., Myers, D., Wilson, A., Rankin, K. P., Allison, S. C., Rosen, H. J., .. . \& Gorno-Tempini, M. L. (2006). The anatomy of category-specific object naming in neurodegenerative diseases. Journal of Cognitive Neuroscience, 18(10), 1644-1653.

Buxbaum, L. J., Shapiro, A. D., \& Coslett, H. B. (2014). Critical brain regions for tool-related and imitative actions: a componential analysis. Brain, 137(7), 1971-1985.

Campanella, F., D’Agostini, S., Skrap, M., \& Shallice, T. (2010). Naming manipulable objects: anatomy of a category specific effect in left temporal tumours. Neuropsychologia, 48(6), 1583-1597.

Carey, S. (2009). Origin of Concepts. Oxford: Oxford University Press.

Chao, L. L., Haxby, J. V, \& Martin, A. (1999). Attributebased neural substrates in temporal cortex for perceiving and knowing about objects. Nature Neuroscience, 2(10), 913-919.

Chatterjee, A. (2008). The neural organization of spatial thought and language. Seminars in Speech and Language, 29(3), 226-238.

Cox, R. W. (1996). AFNI: software for analysis and visualization of functional magnetic resonance neuroimages. Computers and Biomedical Research, an International Journal, 29(3), 162-173.

Damasio, A. R., Tranel, D., Grabowski, T., \& Adolphs, R. (2004). Neural systems behind word and concept retrieval. Cognition, 92, 179-229.

Damasio, H., Grabowski, T., Tranel, D., Hichwa, R. D., \& Damasio, A. R. (1996). A neural basis for lexical retrieval. Nature, 380(11 April).

Doehrmann, O., Naumer, M. J., Volz, S., Kaiser, J., \& Altmann, C. F. (2008). Probing category selectivity for environmental sounds in the human auditory brain. Neuropsychologia, 46(11), 2776-2786.

Futó, J., Téglás, E., Csibra, G., \& Gergely, G. (2010). Communicative function demonstration induces kind-based artifact representation in preverbal infants. Cognition, 117(1), 1-8.

Garcea, F. E., \& Mahon, B. Z. (2014). Parcellation of left parietal tool representations by functional connectivity. Neuropsychologia, 60, 131-143.

Goodman, N. D., Tenenbaum, J. B., Griffiths, T. L., \& Feldman, J. (2012). Compositionality in rational analysis: Grammar-based induction for concept 
learning. In The Probabilistic Mind: Prospects for Bayesian cognitive science.

Gopnik, A., \& Meltzoff, A. N. (1997). Words, Thoughts, and Theories. Cambridge, MA: MIT Press.

Gopnik, A., \& Sobel, D. M. (2000). Detecting blickets: how young children use information about novel causal powers in categorization and induction. Child Development, 71 (5), 1205-1222.

Hernik, M., \& Csibra, G. (2009). Functional understanding facilitates learning about tools in human children. Current Opinion in Neurobiology, 19(1), 34-38.

Isik, L., Koldewyn, K., Beeler, D., \& Kanwisher, N. G. (2017). Perceiving social interactions in the posterior superior temporal sulcus. Proceedings of the National Academy of Sciences, 201714471.

Jones, M., \& Love, B. C. (2007). Beyond common features: The role of roles in determining similarity. Cognitive Psychology, 55(3), 196-231.

Keil, F. C., Smith, W. C., Simons, D. J., \& Levin, D. T. (1998). Two dogmas of conceptual empiricism: implications for hybrid models of the structure of knowledge. Cognition, 65(2-3), 103-135.

Kelemen, D., \& Carey, S. (2007). The essence of artifacts: Developing the design stance. In S. Laurence \& E. Margolis (Eds.), Creations of the Mind: Artifacts and their representation (pp. 415-449). Oxford: Oxford University Press.

Kemler Nelson, D. G., Frankenfield, A., \& Morris, C. (2000). Young children's use of functional information to categorize artifacts: Three factors that matter. Cognition, 77, 133-168.

Kemp, C., Tenenbaum, J. B., Niyogi, S., \& Griffiths, T. L. (2010). A probabilistic model of theory formation. Cognition, 114(2), 165-196.

Konkle, T., \& Caramazza, A. (2013). Tripartite organization of the ventral stream by animacy and object size. ournal of Neuroscience, 33(25), 10235-10242.

Konkle, T., \& Caramazza, A. (2016). The large-scale organization of object-responsive cortex Is reflected in resting-state network architecture. Cerebral Cortex, $27(10), 4933-4945$.

Lambon-Ralph, M. A., Jefferies, E., Patterson, K., \& Rogers, T. T. (2017). The neural and computational bases of semantic cognition. Nature Reviews Neuroscience, $18(1), 42-55$.

Leshinskaya, A., \& Thompson-Schill, S. L. (2019). From the structure of experience to concepts of structure: how the concept "cause" applies to streams of events. Journal of Experimental Psychology-General, 148(4), 619-643.

Leshinskaya, A., Wurm, M. F., \& Caramazza, A. (2020). Concepts of actions and their objects. In M Gazzaniga, GR Mangun, D Poeppel. The Cognitive Neurosciences, 757-765.

Lewis, J. W., Brefczynski, J. A., Phinney, R. E., Janik, J. J., \& DeYoe, E. A. (2005). Distinct cortical pathways for processing tool versus animal sounds. Journal of Neuroscience, 25(21), 5148-5158.

Liu, S., Brooks, N. B., \& Spelke, E. S. (2019). Origins of the concepts cause, cost, and goal in prereaching infants. Proceedings of the National Academy of Sciences of the United States of America, 116(36), 17747-17752.

Lombrozo, T., \& Rehder, B. (2012). Functions in biological kind classification. Cognitive Psychology, 65(4), 457-485.

Long, B., Yu, C. P., \& Konkle, T. (2018). Mid-level visual features underlie the high-level categorical organization of the ventral stream. Proceedings of the National Academy of Sciences of the United States of America, 115(38), E9015-E9024.

Magri, C., Konkle, T., \& Caramazza, A. (2016). Visual object responses of the ventral stream reflect both size and motor-relevance. Journal of Vision, 16(12), 505.

Mahon, B. Z., Anzellotti, S., Schwartzbach, J., Zampini, M., \& Caramazza, A. (2009). Category-specific organization in the human brain does not require visual experience. Neuron, 63, 297-405.

Mahon, B. Z., Schwarzbach, J., \& Caramazza, A. (2010). The representation of tools in left parietal cortex is independeant of visual experience. Psychological Science, 21 (6), 764-771.

Malt, B. C., \& Johnson, E. C. (1992). Do artifact concepts have cores? Journal of Memory and Language, $31(2), 195-217$.

Markman, A. B., \& Stilwell, C. H. (2001). Role-governed categories. Journal of Experimental \& Theoretical Artificial Intelligence, 13(4), 329-358.

Martin, A. (2007). The representation of object concepts in the brain. Annual Review of Psychology, 58, 25-45.

Martin, A., \& Weisberg, J. (2003). Neural foundations for understanding social and mechanical concepts. Cognitive Neuropsychology, 20(3-6), 575-587.

Martin, A., Wiggs, C. L., Ungerleider, L. G., \& Haxby, J. V. (1996). Neural Correlates of Category Specific Knowledge. Nature, 379(15 February), 649-652.

Mattioni, S., Rezk, M., Battal, C., Bottini, R., Mendoza, K. E. C., Oosterhof, N. N., \& Collignon, O. (2020). Categorical representation from sound and sight in the ventral occipito-temporal cortex of sighted and blind. ELife, 9, 1-33.

Nazzi, T., \& Gopnik, A. (2003). Sorting and acting with objects in early childhood: An exploration of the use of causal cues. Cognitive Development, 18(3), 299-317.

Noppeney, U., Price, C. J., Penny, W. D., \& Friston, K. J. (2006). Two distinct neural mechanisms for category-selective responses. Cerebral Cortex, 16(3), $437-445$. 
Oakes, L. M., \& Madole, K. L. (2008). Function revisited: How infants construe functional features in their representation of objects. In Advances in child development and behavior, 36, 135-185.

Oosterhof, N. N., Wiggett, A. J., Diedrichsen, J., Tipper, S. P., \& Downing, P. E. (2010). Surface-based information mapping reveals crossmodal vision-action representations in human parietal and occipitotemporal cortex. Journal of Neurophysiology, 104(2), 1077-1089.

Patterson, K., Nestor, P. J., \& Rogers, T. T. (2007). Where do you know what you know? The representation of semantic knowledge in the human brain. $\mathrm{Na}$ ture Reviews Neuroscience, 8(December), 976-989.

Peelen, M. V., Bracci, S., Lu, X., He, C., Caramazza, A., \& Bi, Y. (2013). Tool selectivity in left occipitotemporal cortex develops without vision. Journal of Cognitive Neuroscience, 25(8), 1225-123.

Schulz, L. E., Goodman, N. D., Tenenbaum, J. B., \& Jenkins, A. (2008). Going beyond the evidence: Abstract laws and preschoolers' responses to anomalous data. Cognition, 109, 211-223.

Schulz, L. E., \& Gopnik, A. (2004). Causal learning across domains. Developmental Psychology, 40(2), $162-176$.

Simmons, W. K., \& Martin, A. (2011). Spontaneous resting-state BOLD fluctuations reveal persistent domain-specific neural networks. Social Cognitive and Affective Neuroscience, 7(4), 467-475.

Striem-Amit, E., Vannuscorps, G., \& Caramazza, A. (2017). Sensorimotor-independent development of hands and tools selectivity in the visual cortex. Proceedings of the National Academy of Sciences, 201620289.

Striem-Amit, E., Vannuscorps, G., \& Caramazza, A. (2018). Plasticity based on compensatory effector use in the association but not primary sensorimotor cortex of people born without hands. Proceedings of the National Academy of Sciences, 201803926.

Tarhan, L. Y., Watson, C. E., \& Buxbaum, L. J. (2016). Shared and distinct neuroanatomic regions critical for tool-related action production and recognition: Evidence from 131 left-hemisphere stroke patients. Journal of Cognitive Neuroscience, 27(12), 2491-2511.

Tranel, D., Damasio, H., \& Damasio, A. R. (1997). A neural basis for the retrieval of conceptual knowledge. Neuropsychologia, 35(10), 1319-1327.

Träuble, B., \& Pauen, S. (2011). Cause or effect: what matters? How 12-month-old infants learn to categorize artifacts. The British Journal of Developmental Psychology, 29(3), 357-374.

Truxaw, D., Krasnow, M. M., Woods, C., \& German, T. P. (2006). Conditions under which function information attenuates name extension via shape. Psychological Science, 17(5), 367-371.
Ullman, S., Harari, D., \& Dorfman, N. (2012). From simple innate biases to complex visual concepts. Proceedings of the National Academy of Sciences, 109(44), 18215-18220.

Valyear, K. F., Cavina-Pratesi, C., Stiglick, A. J., \& Culham, J. C. (2007). Does tool-related fMRI activity within the intraparietal sulcus reflect the plan to grasp? NeuroImage, 36, T94-T108.

Vannuscorps, G., Wurm, M. F., Striem-Amit, E., \& Caramazza, A. (2018). Large-scale organization of the hand action observation network in individuals born without hands. Cerebral Cortex, 29(8), 34343444

Vingerhoets, G., Acke, F., Vandemaele, P., \& Achten, E. (2009). Tool responsive regions in the posterior parietal cortex: effect of differences in motor goal and target object during imagined transitive movements. NeuroImage, 47(4), 1832-1843.

Waismeyer, A., Meltzoff, A. N., \& Gopnik, A. (2014). Causal learning from probabilistic events in 24month-olds: an action measure. Developmental Science, 18(1), 175-182.

Weisberg, J., van Turennout, M., \& Martin, A. (2007). A neural system for learning about object function. Cerebral Cortex, 17(3), 513-521.

Wurm, M. F., \& Lingnau, A. (2015). Decoding actions at different levels of abstraction. The Journal of Neuroscience, 35(20), 7727-7735.

Yee, E., Drucker, D. M., \& Thompson-Schill, S. L. (2010). fMRI-adaptation evidence of overlapping neural representations for objects related in function or manipulation. NeuroImage, 50(2), 753-763.

Yee, E., Huffstetler, S., \& Thompson-Schill, S. L. (2011). Function follows form: activation of shape and function features during object identification. Journal of Experimental Psychology. General, 140(3), 348-363. 
8 SUPPLEMENTAL MATERIAL 

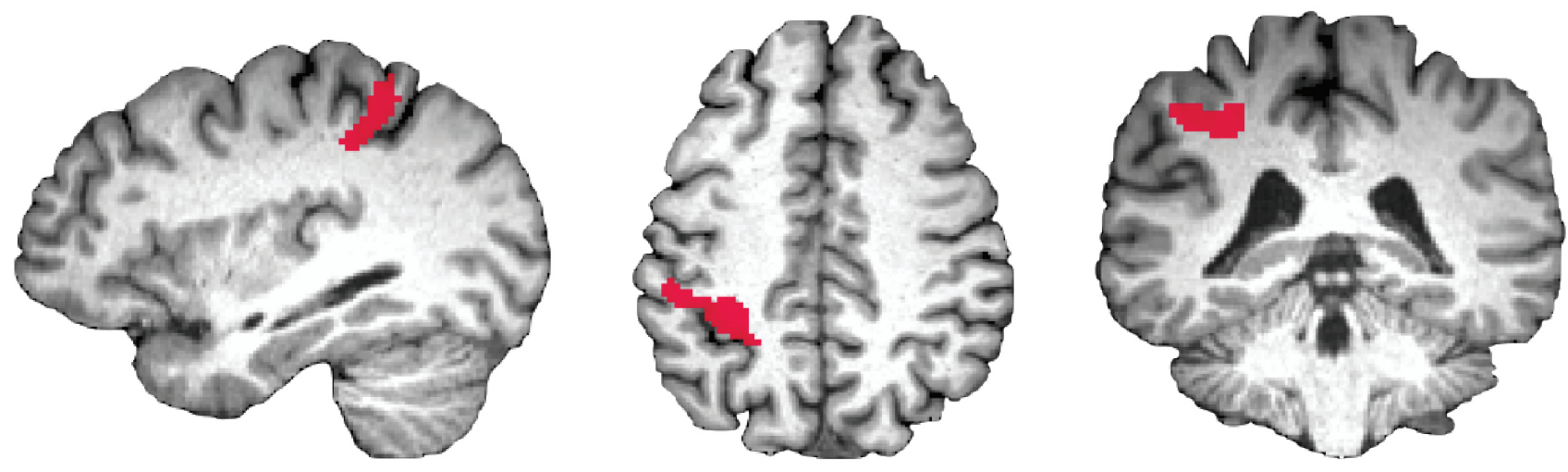

Figure 7. Figure S1. Group-average cluster from the localizer contrast Tools $>$ Non-Tools used as the IPS ROI.

Table S4 Results from Movement $\times$ Causality ANOVA in Non-Tool-Selective Areas

\begin{tabular}{|c|c|c|c|c|c|c|c|c|c|}
\hline \multicolumn{10}{|c|}{$\mathrm{rOCC}$} \\
\hline & $\begin{array}{l}\text { Self-Causer } \\
\quad M(S D)\end{array}$ & $\begin{array}{l}\text { Self-Reactor } \\
\qquad M(S D)\end{array}$ & $\begin{array}{c}\text { Hand-Causer } \\
M(S D)\end{array}$ & $\begin{array}{l}\text { Hand-Reactor } \\
\qquad M(S D)\end{array}$ & $\begin{array}{c}\text { Causality } \\
\text { Main Effect }\end{array}$ & $\begin{array}{l}\text { Movement } \\
\text { Main Effect }\end{array}$ & $\begin{array}{c}\text { Movement } \times \text { Causality } \\
\text { Interaction }\end{array}$ & $\begin{array}{l}\text { Causality Within Self } \\
\text { Simple Effect }\end{array}$ & $\begin{array}{c}\text { Causality Within Hand } \\
\text { Simple Effect }\end{array}$ \\
\hline 25 voxels & $2.16(3.35)$ & $1.90(3.30)$ & $1.98(3.57)$ & $2.13(3.30)$ & $\begin{array}{l}F=0.09 \\
p=.768\end{array}$ & $\begin{array}{l}F=0.13 \\
p=.723\end{array}$ & $\begin{array}{l}F=1.56 \\
p=.222\end{array}$ & $\begin{array}{l}F=1.40 \\
p=.245\end{array}$ & $\begin{array}{l}F=0.23 \\
p=.633\end{array}$ \\
\hline 50 voxels & $2.32(3.07)$ & $2.07(3.07)$ & $2.13(3.25)$ & $2.32(3.05)$ & $\begin{array}{l}F=0.03 \\
p=.862\end{array}$ & $\begin{array}{l}F=0.17 \\
p=.684\end{array}$ & $\begin{array}{l}F=1.96 \\
p=.171\end{array}$ & $\begin{array}{l}F=1.50 \\
p=.230\end{array}$ & $\begin{array}{l}F=0.42 \\
p=.521\end{array}$ \\
\hline 100 voxels & $2.17(2.45)$ & $1.96(2.50)$ & $1.99(2.67)$ & $2.20(2.54)$ & $\begin{array}{l}F=0.01 \\
p=.933\end{array}$ & $\begin{array}{l}F=0.14 \\
p=.712\end{array}$ & $\begin{array}{l}F=1.97 \\
p=.170\end{array}$ & $\begin{array}{l}F=1.26 \\
p=.271\end{array}$ & $\begin{array}{l}F=0.53 \\
p=.474\end{array}$ \\
\hline 200 voxels & $2.20(2.20)$ & $2.02(2.19)$ & $2.05(2.30)$ & $2.22(2.17)$ & $\begin{array}{l}F=0.02 \\
p=.902\end{array}$ & $\begin{array}{l}F=0.22 \\
p=.645\end{array}$ & $\begin{array}{l}F=1.56 \\
p=.222\end{array}$ & $\begin{array}{l}F=1.05 \\
p=.314\end{array}$ & $\begin{array}{l}F=0.35 \\
p=.556\end{array}$ \\
\hline \multicolumn{10}{|c|}{$1 \mathrm{OCC}$} \\
\hline & $\begin{array}{l}\text { Self-Causer } \\
\quad M(S D)\end{array}$ & $\begin{array}{l}\text { Self-Reactor } \\
\qquad M(S D)\end{array}$ & $\begin{array}{c}\text { Hand-Causer } \\
\qquad M(S D) \\
\end{array}$ & $\begin{array}{l}\text { Hand-Reactor } \\
\qquad M(S D)\end{array}$ & $\begin{array}{c}\text { Causality } \\
\text { Main Effect }\end{array}$ & $\begin{array}{c}\text { Movement } \\
\text { Main Effect }\end{array}$ & $\begin{array}{c}\text { Movement } \times \text { Causality } \\
\text { Interaction }\end{array}$ & $\begin{array}{c}\text { Causality Within Self } \\
\text { Simple Effect }\end{array}$ & $\begin{array}{c}\text { Causality Within Hand } \\
\text { Simple Effect }\end{array}$ \\
\hline 25 voxels & $2.35(2.99)$ & $2.32(3.01)$ & $2.43(3.22)$ & $2.48(2.92)$ & $\begin{array}{l}F=0.00 \\
p=.999\end{array}$ & $\begin{array}{l}F=0.24 \\
p=.628\end{array}$ & $\begin{array}{l}F=0.06 \\
p=.805\end{array}$ & $\begin{array}{l}F=0.01 \\
p=.940\end{array}$ & $\begin{array}{l}F=0.01 \\
p=.940\end{array}$ \\
\hline 50 voxels & $2.09(2.54)$ & $2.07(2.58)$ & $2.15(2.81)$ & $2.17(2.59)$ & $\begin{array}{l}F=0.02 \\
p=.901\end{array}$ & $\begin{array}{l}F=0.13 \\
p=.722\end{array}$ & $\begin{array}{l}F=0.02 \\
p=.893\end{array}$ & $\begin{array}{l}F=0.01 \\
p=.945\end{array}$ & $\begin{array}{l}F=0.01 \\
p=.914\end{array}$ \\
\hline 100 voxels & $2.25(2.48)$ & $2.21(2.48)$ & $2.25(2.72)$ & $2.33(2.61)$ & $\begin{array}{l}F=0.00 \\
p=.979\end{array}$ & $\begin{array}{l}F=0.09 \\
p=.772\end{array}$ & $\begin{array}{l}F=0.15 \\
p=.702\end{array}$ & $\begin{array}{l}F=0.03 \\
p=.871\end{array}$ & $\begin{array}{l}F=0.04 \\
p=.850\end{array}$ \\
\hline 200 voxels & $2.43(2.24)$ & $2.41(2.24)$ & $2.43(2.34)$ & $2.54(2.40)$ & $\begin{array}{l}F=0.06 \\
p=.814\end{array}$ & $\begin{array}{l}F=0.14 \\
p=.714\end{array}$ & $\begin{array}{l}F=0.15 \\
p=.702\end{array}$ & $\begin{array}{l}F=0.00 \\
p=.976\end{array}$ & $\begin{array}{l}F=0.10 \\
p=.754\end{array}$ \\
\hline
\end{tabular}

Note: all ANOVA degrees of freedom are $(1,30)$ 
Table S5 Results from ROI $\times$ Movement $\times$ Causality ANOVA in OCC

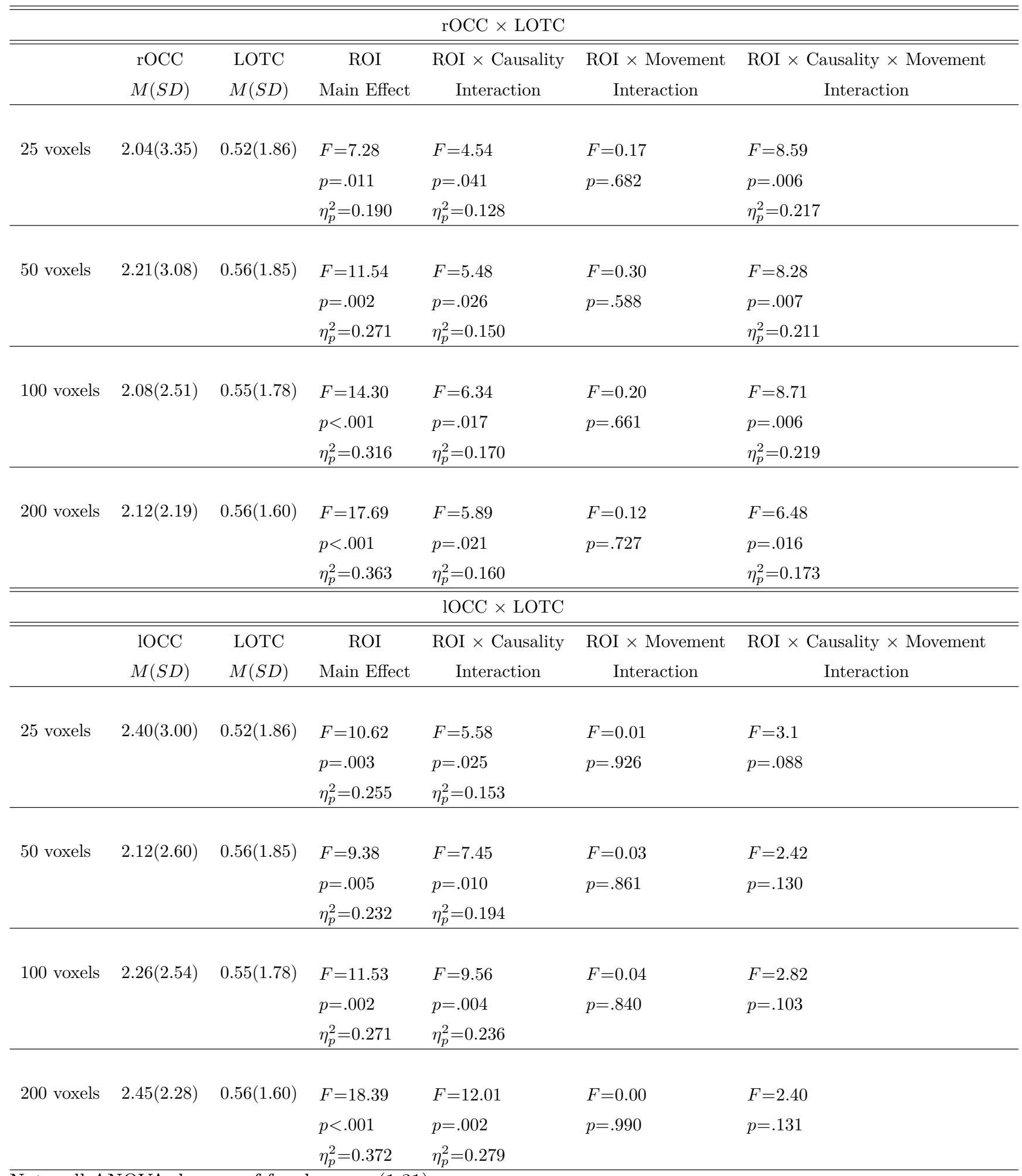

Note: all ANOVA degrees of freedom are $(1,31)$ 